\title{
Insolvency administrator's incentives and the tradeoff between creditor satisfaction and efficiency in bankruptcy procedures
}

\author{
Matthias Frieden ${ }^{1}$ (D) Stefan Wielenberg ${ }^{1}$
}

Received: 22 June 2016/ Accepted: 25 May 2017/Published online: 3 June 2017

(C) The Author(s) 2017. This article is an open access publication

\begin{abstract}
An insolvency administrator replaces the manager of an insolvent firm to devise and organize a liquidation or reorganization plan in the creditors' interest. In the course of the process, the insolvency administrator presents the most favourable option from his perspective, and the creditors choose to accept or reject this plan. Conflicts of interest arise because the insolvency administrator, as the better-informed party, considers in his proposal liability risks and reputational issues that are beyond the creditors' scope. We model this conflict as a Bayesian game and find that, under those compensation schemes typically used in real-world regulations, optimal creditor satisfaction and efficient decisions concerning the economic future of the insolvent firm will never be achieved simultaneously.
\end{abstract}

Keywords Bankruptcy · Insolvency administrator · Creditor · Incentives · Compensation

\begin{abstract}
We would like to thank Joachim Gassen, Thomas Gehrig, Ulf Schiller, Georg Schneider, Dirk Simons, two anonymous referees and the participants at the ARFA workshop 2016 in Graz as well as seminar participants at the 2016 VHB Jahrestagung in Munich and the participants at the GEABA Symposium 2016 in Basel for helpful comments and discussions.
\end{abstract}

Matthias Frieden

frieden@rewp.uni-hannover.de

Stefan Wielenberg

wielenberg@rewp.uni-hannover.de

1 Department of Economics, Leibniz-University Hanover, Koenigsworther Platz 1, 30167 Hanover, Germany 


\section{Introduction}

The objective of a bankruptcy law concerns two primary aspects: first, it should ensure optimal creditor satisfaction by exploiting the remaining assets of a bankrupt firm, and second, it should separate viable from unviable bankrupt firms. However, identifying the viability of firms is a difficult task, generating two types of errors: Type I error occurs if unviable firms are restructured under court-supervised reorganization. Type II error occurs when viable firms are liquidated instead of reorganized (White 1994). These two errors constitute the filtering failure of an insolvency procedure.

The literature discusses various reasons for this filtering failure. The most commonly considered explanation is asymmetric information between creditors and managers or equity holders, which impedes the information revelation process regarding the true value of a financially distressed firm (Hotchkiss et al. 2008; Giammarino 1989; Li and Li 1999; Mooradian 1994; White 1994). Further studies analyse the influence of biased judges (Bris et al. 2005; Baird 1986) or the quality and judicial discretion of judges on the ex post outcome of a bankruptcy procedure (Ayotte and Yun 2007; Bernhardt and Nosal 2004). Another issue discussed in the literature is the conflict of interest among multiple creditors (Blazy and Chopard 2004) or the problems due to multiple classes of creditors (Bulow and Shoven 1978; White 1989; Gertner and Scharfstein 1991).

This paper addresses the individual incentives of a better-informed insolvency administrator as an additional source of filtering failure. We incorporate asymmetric information, individual concerns, such as liability risks or reputational issues, and insolvency administrator remuneration in a stylized model in which the interactions between the insolvency administrator and the creditors of a company are analysed. Our key contribution is that the insolvency administrator compensation schemes typically used in insolvency law will not imply optimal creditor satisfaction and the absence of filtering failure simultaneously. The main driver of this result is the information asymmetry between the involved parties in combination with the individual concerns of the insolvency administrator. The insolvency administrator will always report the true viability of the bankrupt firm and will always propose the correct resolution of a bankruptcy under an appropriate compensation scheme. However, providing these incentives is not optimal from the creditor's perspective.

Besides from compensation schemes typically used in insolvency law, we derive a compensation scheme that simultaneously implies optimal creditor satisfaction and no filtering failure as a benchmark. However, such a scheme heavily depends on the unverifiable preferences of the individual insolvency administrator and will therefore not be implementable as a general regulation. We argue that regulatory measures addressing liability risk or the role of reputation are more appropriate to enhance the efficiency of insolvency proceedings.

To the best of our knowledge, this is the first study to analyse the influence of insolvency administrators' incentives on the ex post efficiency of a bankruptcy law. This article contributes to the theoretical literature on the information asymmetry among creditors, owner-managers and third parties such as judges as a source of 
filtering failure. White (1994) investigates the filtering properties of U.S. bankruptcy law. In that model, a manager can decide to file for Chapter 11 or Chapter 7 bankruptcy, and the results indicate that pooling equilibria exist in which efficient and inefficient bankrupt firms reorganize under chapter 11 and, therefore, Type I errors occur. Furthermore, Giammarino (1989) and Li and Li (1999) study how a formal bankruptcy procedure can help resolve the information problem between a manager/firm and a creditor. They analyse whether it is optimal to incur costs due to a bankruptcy procedure, given the existence of the costless alternative of a private renegotiation. The role of bankruptcy law is to force information disclosure and to resolve information asymmetry. In contrast to these papers, we analyse the information revelation process within a court-supervised procedure after private renegotiation between the firm and its creditors has failed. Moreover, we consider the relationship between an insolvency administrator and a creditor.

Ayotte and Yun (2007) analyse the effect of the quality of judges or insolvency administrators on the ex post outcome of a bankruptcy procedure. They find that judicial expertise is necessary when creditors are biased, using the following argumentation: When creditors are biased towards liquidation, a more debtorfriendly bankruptcy law in which management is allowed to retain some control will be efficient. Therefore, this freedom in managers' decisions necessarily requires judicial expertise to separate viable and unviable bankrupt firms. In contrast, if the judges' ability to identify viable firms is low, a more creditor-friendly bankruptcy law will be optimal. Bernhardt and Nosal (2004) also analyse how judicial discretion influences the outcome of a bankruptcy. They show that some judicial error can enhance the ex post efficiency of a bankruptcy procedure due to better ex ante actions on the part of management. In contrast, we investigate the influence of the insolvency administrator's remuneration on the ex post outcome and do not distinguish different qualities or discretion of an insolvency administrator. Moreover, in our model, an insolvency administrator has divergent incentives from those of a judge. The insolvency administrator is not employed by the government, is personally liable for his decisions and needs a good reputation to be assigned to future insolvency procedures.

A second strand of the literature empirically examines the reasons for ex post inefficiency. For example, Djankov et al. (2008) use a case study presented to lawyers in 88 countries to measure the concrete extent of inefficiency. They find that bankruptcy procedures in all countries are highly inefficient. Therefore, the main reasons for inefficiency are high administrative costs and long time delays. The study contains several countries with an insolvency administrator as an integral part of the bankruptcy procedure, but they do not separately analyse how the insolvency administrator should be remunerated. Only one empirical study considers the influence of an insolvency administrator's compensation scheme on the bankruptcy outcome. Using Hungarian data, Franks and Loranth (2013) find an impact of the insolvency administrator's remuneration on the satisfaction of creditors and argue that one reason for high bankruptcy costs might be the structure of the remuneration scheme for insolvency administrators. Our paper can be understood as a theoretical basis for the inefficiencies mentioned in Franks and Loranth (2013). 
The remainder of this paper is structured as follows. Section 2 outlines the role and the remuneration of the insolvency administrator in the German Insolvency Code. Section 3 presents the model, and Sect. 4 analyses the different equilibria of the game. Section 5 analyses the efficiency of the insolvency administrator's compensation. Some implications for the regulation of insolvency procedures are discussed in Sect. 6, and the final section concludes the paper.

\section{The German insolvency procedure}

The insolvency administrator is of particular importance in the German Insolvency Code; therefore, we use the German insolvency procedure as the basis for our analysis. Nonetheless, our study is not limited to Germany, as insolvency administrators are common in many insolvency codes. ${ }^{1}$ German insolvency proceedings begin after creditors or the management of the bankrupt firm declare insolvency. The reasons for such a declaration are illiquidity, impeding illiquidity or over-indebtedness (Sec. 16 et seq. Insolvenzordnung (InsO)). In a next step, an insolvency judge examines whether the remaining assets are sufficient to cover the insolvency costs (Sec. 26 InsO and Haarmeyer, in: Kirchhof et al. (2014), to Sec. 26, Note 11) and delegates the responsibility and management of the bankrupt firm to an insolvency administrator (Sec. 27 (1) InsO). Thereafter, the insolvency administrator must continue operations, secure remaining assets and develop options for the future of the firm. During this time, the insolvency administrator privately obtains information about the viability and conditions of the firm and therefore learns whether a liquidation or continuation of the bankrupt firm is beneficial.

At most three months after the beginning of the insolvency procedure, the insolvency administrator reports on the potential future options for the bankrupt firm at the creditors' meeting ( $\mathrm{Sec} .156 \mathrm{InsO}$ ). On the basis of this report, creditors decide to liquidate and shut down the firm or to continue the firm. Furthermore, they can enable the insolvency administrator to devise an insolvency plan (Sec. 157 InsO). The main purpose of such an insolvency plan is the development of a detailed proposal on how the bankrupt firm can be reorganized.

According to German bankruptcy law, an insolvency administrator's compensation depends on the total amount of the insolvency assets realized in the insolvency procedure and on the compensation parameters defined by the insolvency code. The monetary compensation is typically defined as a share of the realized assets (Sec. 1 et seq. Insolvenzrechtliche Verguetungsverodnung $($ InsVV)). From this compensation, the insolvency administrator has to pay his general administrative costs (Sec. 4 InsVV). However, in the event of a highly complex procedure, a reorganization of the firm or a preparation of an insolvency plan, the insolvency court can individually adjust the compensation parameters (Sec. 3 InsVV and Haarmeyer et al. (2007), to Sec. 3, Note 8 et seq.).

\footnotetext{
1 Insolvency administrators or trustees are most frequent in European countries. See Appendix A for a comparison of selected international insolvency procedures.
} 
In addition, the insolvency administrator's incentives contain elements other than monetary remuneration. These are the uncompensated costs or non-monetary benefits of the insolvency administrator. Uncompensated costs arise from litigation or liability risks (for example, Sec $60 \mathrm{InsO}$ and Brandes/Schoppmeyer, in: Kirchhof et al. (2014), to Sec. 60, Note 89-91). Legal liabilities and litigation costs are prevalent in reorganizations because the insolvency administrator has to manage the bankrupt firm and to develop a sustainable business model in a continuation. During this task, creditors may believe that the administrator's decisions are negligent or wrong. Additionally, he vouches for all debt issued during the insolvency. Thus, creditors may sue the insolvency administrator for damage payments as a party with deep pockets and not only in situations in which a reorganization plan fails.

In contrast to uncompensated costs, reputational effects may imply non-monetary benefits. Reputation arises primarily in a reorganization of the insolvent firm because the insolvency administrator can demonstrate his ability to develop a sustainable business model and to maintain the firm as a going concern. Restructuring a firm under time constraints is a highly complex task. The insolvency administrator has to develop a profound, firm-specific understanding in a very short time. Hence, he needs high cognitive skills and high managerial knowhow. Therefore, the reorganization of an insolvent firm can be seen as a positive signal that helps the insolvency administrator be assigned to profitable future insolvency procedures. For example, the German government implemented an insolvency law reform in 2011 intended to encourage the reorganization of insolvent firms. ${ }^{2}$ This amendment also affects the value of the insolvency administrator's reputation: Prior to the reform, the insolvency court assigned an insolvency administrator to the insolvent firm. The court had to choose the insolvency administrator from a list and, thus, had considerable leeway. Overall, this process was rather obscure. Under the new law, creditors can propose an insolvency administrator (Sec. 56a InsO).

\section{The game between the insolvency administrator and the creditor}

The discussion of the German insolvency code in Sect. 2 and Table 1 in Appendix A reveals the following stylized facts concerning the interactions between the insolvency administrator and the creditors:

1. Insolvency administrators are better informed about the future options of the insolvent firm.

2. They propose the potential usage (liquidation or continuation), which has to be approved by the creditors.

3. The insolvency administrator's compensation can entail fixed and variable components, depending on the value of assets under continuation or liquidation.

We consider these stylized facts in a Bayesian sequential game between the insolvency administrator and a creditor. To rule out different interests and free-rider

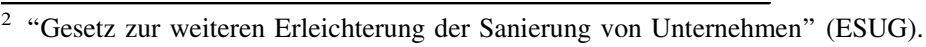




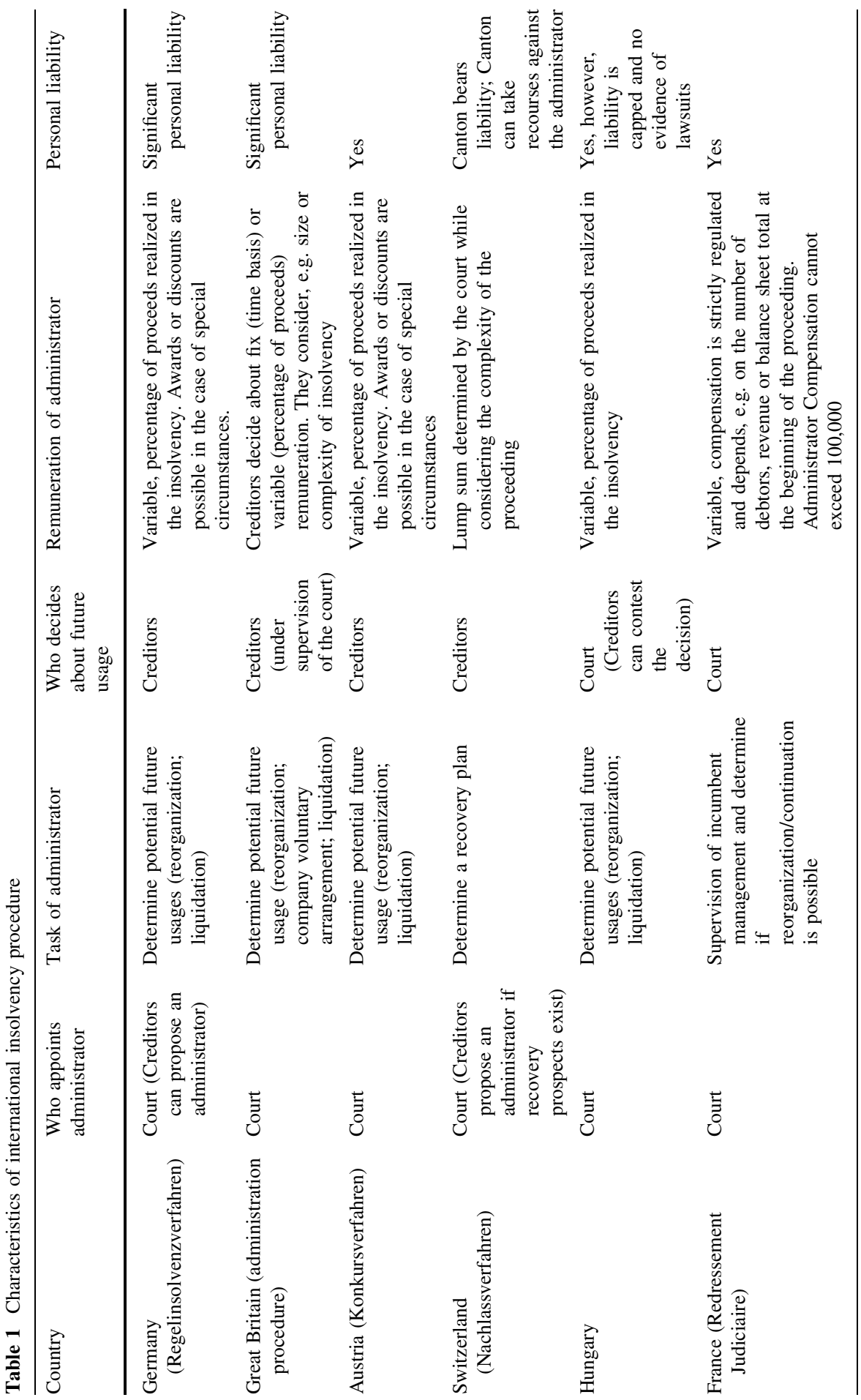


problems among creditor groups, we model the multitude of creditors typical for real-world insolvency cases as a single player.

At the beginning of the game, a firm declares insolvency, and the official insolvency procedure starts. Figure 1 summarizes and illustrates the game. First, the insolvency court delegates the responsibility and management of the insolvent firm to an insolvency administrator. During this time, the insolvency administrator privately obtains information on the viability of the firm, denoted by $\theta$. We understand that firms with high $\theta$ exhibit high viability: they have a sustainable business model and good future prospects. Low $\theta$ means the opposite: these firms cannot survive in the market on a sustainable basis. The creditor does not obtain this information but has a prior belief about $\theta$, given by a uniform distribution with support by $[0,1]$.

With knowledge of $\theta$, the insolvency administrator can determine the value of the firm's assets depending on liquidation or continuation. In a continuation, the firm is reorganized and operations continue. A liquidation will result in a sale of the assets and in a shutdown of the firm. For the sake of simplicity, we normalize the liquidation value to 1 . The value in a continuation increases with $\theta$ but is not perfectly predictable as a result of uncertain future events. In a continuation, the value accounts for $2 \theta+\varepsilon$ with $E(\varepsilon)=0, \operatorname{Var}(\varepsilon)=\sigma^{2}$ and $\operatorname{Cov}(\theta, \varepsilon)=0$. Thus, the expected continuation value is $2 \theta$. Due to our assumptions, liquidation values are higher for small $\theta$ and continuation values for large $\theta$. Both expected values are equal at $\theta=1 / 2$.

In the next stage, the insolvency administrator reports his favoured option to the creditor. The creditor then decides whether to follow or to reject the proposal. This decision critically depends on the creditor's conditional expected payoffs for both alternatives, which we derive below. If the creditor accepts the proposal, the insolvency administrator will carry out his decision and the game ends.

Motivated by the discussion of the German insolvency code, we assume that the insolvency administrator's payoff is proportional to the value realized in the insolvency procedure. ${ }^{3}$ The shares can depend on liquidation and continuation and are denoted as $\beta_{0}$ (liquidation) and $\beta_{1}$ (continuation). To keep things simple, we abstract from any direct expenses of the insolvency administrator for preparing and performing the plan if the plan is accepted by the creditors and implemented.

However, we consider expected uncompensated costs $\left(u_{\mathrm{L}}, u_{\mathrm{C}}\right)$ and non-monetary benefits $\left(r_{\mathrm{L}}, r_{\mathrm{C}}\right)$ in our model. As motivated in Sect. 2, we assume that $u_{\mathrm{L}}=0$ and $r_{\mathrm{L}}=0$ in a liquidation scenario. In a continuation scenario, we define $u_{\mathrm{C}}=u(\theta)$ and $r_{\mathrm{C}}=r(\theta)$. Uncompensated costs typically decrease in $\theta$ because litigation and liability risks become less likely for high $\theta$. For the sake of simplicity, we set $u(\theta)=(1-\theta) u$. We also assume that the non-monetary benefits increase in $\theta$ because an insolvency administrator can better demonstrate his abilities to maintain a firm as going concern for more valuable firms. Again, we assume a linear relation and set $r(\theta)=\theta r$ and obtain $\theta r-(1-\theta) u$ as the total amount of uncompensated costs and benefits.

\footnotetext{
${ }^{3}$ We discuss a fixed compensation that differentiates only between liquidation and continuation and between a compensation—inducing no filtering failure—and optimal creditor satisfaction in Sect. 5.
} 


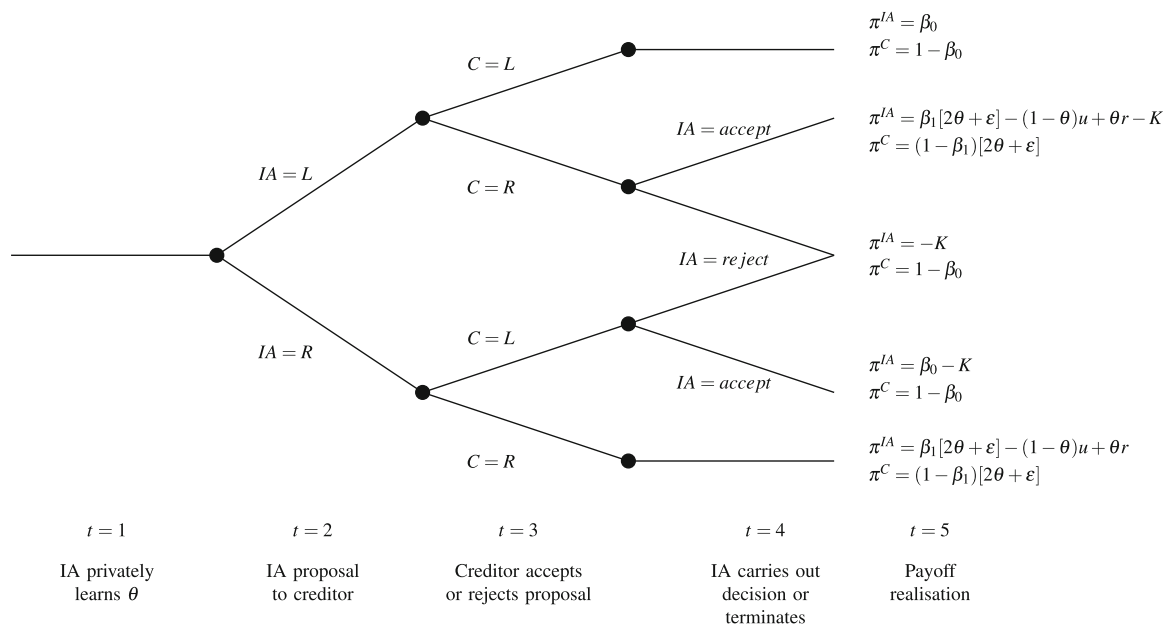

Fig. 1 Bayesian game between insolvency administrator (IA) and creditor (C). After observing $\theta$, the insolvency administrator can propose liquidation (L) or continuation (R). The creditor can confirm the proposal (claiming $\mathrm{R}$ upon $\mathrm{R}$ or $\mathrm{L}$ upon $\mathrm{L}$ ) or reject (claiming $\mathrm{L}$ on $\mathrm{R}$ or $\mathrm{R}$ on $\mathrm{L}$ ). In the event of a rejection, the insolvency administrator may accept the creditor's claim or terminate

If the creditors accept the insolvency administrator's proposal, the game ends and we can define the payoffs of both parties depending on liquidation and continuation. The insolvency administrator's payoffs for continuation and liquidation are

$$
\pi^{\mathrm{IA}}\left(\theta, \beta_{1}, \varepsilon, u, r\right)=\beta_{1}[2 \theta+\varepsilon]-(1-\theta) u+\theta r
$$

and

$$
\pi^{\mathrm{IA}}\left(\beta_{0}\right)=\beta_{0} .
$$

The creditor's payoff for continuation and liquidation are given by

$$
\pi^{\mathrm{C}}\left(\theta, \beta_{1}, \varepsilon\right)=\left(1-\beta_{1}\right)[2 \theta+\varepsilon]
$$

and

$$
\pi^{\mathrm{C}}\left(\beta_{0}\right)=1-\beta_{0} .
$$

The game continues if the creditor rejects the insolvency administrator's proposal and asks for continuation upon a liquidation proposal and vice versa. In this case, the insolvency administrator can either follow the creditor's proposal or terminate his assignment. In both cases, the rejection of the proposal creates disutility $K$ for the insolvency administrator because he prefers not to work for the trash can. $K$ may also represent costly negotiations with the creditors that especially appear in case of a plan rejection.

The insolvency administrator will always follow the creditor's claim for a liquidation as long as $\beta_{0} \geq 0$. In the event of a continuation claim (instead of a proposed liquidation), the insolvency administrator will leave the job if 


$$
2 \beta_{1} \theta-(1-\theta) u+\theta r-K<-K \Leftrightarrow \theta<\frac{u}{2 \beta_{1}+u+r}:=\theta_{\mathrm{P}} .
$$

As a result of the termination, a new insolvency administrator is hired. The new insolvency administrator will also propose liquidation because $\theta<\theta_{\mathrm{P}}$. Without explicit modelling, we simply assume that the creditor always accepts liquidation because the resignation of the first insolvency administrator is a credible signal.

\section{Equilibrium analysis}

In this section, we examine the equilibria of the game between the insolvency administrator and the creditor. The equilibrium concept used is perfect Bayesian or sequential equilibrium, as the game is similar to a signalling game. In our model, the creditor will use the insolvency administrator's proposal as a signal and he will update his beliefs about $\theta$. Using the updated beliefs, he will accept or reject the proposal. Under perfect Bayesian equilibrium, the insolvency administrator's reporting strategy and the creditor's reaction to the report are best responses given Bayesian updating.

This paper focusses on two questions: (1) How does the insolvency administrator's compensation influence the separation of viable from unviable financially distressed firms, such that no filtering failure occurs? (2) Can no filtering failure and optimal creditor satisfaction be implemented simultaneously by an appropriate compensation regime? As a first consequence of this focus, we concentrate our analysis on separating equilibria and do not consider any pooling equilibrium, as pooling equilibria will never be efficient. In a separating equilibrium, the insolvency administrator proposes liquidation for a subset $\Theta_{\mathrm{L}} \in \Theta=[0,1]$ and continuation of the firm for $\Theta_{\mathrm{C}}=\Theta \backslash \Theta_{\mathrm{L}}$. As a second consequence of our focus, we restrict our attention to those values of $\beta_{0}$ for which a compensation parameter $\beta_{1}^{*}\left(\beta_{0}\right)$ exists, such that $\beta_{0}$ and $\beta_{1}^{*}\left(\beta_{0}\right)$ induce a no filtering failure equilibrium.

Depending on the compensation parameters, we identify three different types of separating equilibria in our model, which are characterized as follows:

1. Pure strategy equilibrium: The insolvency administrator proposes liquidation if $0 \leq \theta \leq \theta^{*}$ and continuation if $\theta^{*}<\theta \leq 1$. The creditor always accepts the proposal. The pure strategy equilibrium without filtering failure is characterized by $\theta^{*}=\frac{1}{2}$.

2. Mixed strategy equilibrium with mistrusted continuation: The insolvency administrator proposes liquidation if $0 \leq \theta \leq \theta^{* *}$ and continuation if $\theta^{* *}<\theta \leq 1$. The creditor always accepts the liquidation proposal and accepts continuation with probability $p^{r}$.

3. Mixed strategy equilibrium with mistrusted liquidation: The insolvency administrator proposes liquidation if $0 \leq \theta \leq \theta^{* * *}$ and continuation if $\theta^{* * *}<\theta \leq 1$. The creditor always accepts the continuation proposal and accepts liquidation with probability $p^{l}$. 
Proposition 1 states how the three different separating equilibria depend on the compensation parameters $\beta_{1}$ and $\beta_{0}$ if uncompensated costs dominate $(u>r)$.

Proposition 1 Suppose that $u>r>0$, and $0 \leq \beta_{0}<1+\frac{3}{2}(r-u)$. Then, the compensation parameters $\beta_{0}$ and $\beta_{1}$ induce the following equilibria:

1. A pure strategy equilibrium with $\theta^{*}=\frac{\beta_{0}+u}{2 \beta_{1}+u+r}$ exists if $\beta_{1}$ and $\beta_{0}$ are such that $\underline{\beta}_{1} \leq \beta_{1} \leq \bar{\beta}_{1}$. The no filtering failure equilibrium $\theta^{*}=\frac{1}{2}$ is induced for $\beta_{1}^{*}=\beta_{0}+\frac{u-r}{2} \in\left(\underline{\beta}_{1}, \bar{\beta}_{1}\right)$.

2. The mixed strategy equilibrium with mistrusted continuation emerges if $\bar{\beta}_{1}<\beta_{1}<\beta_{1}^{\max }$. The threshold value is given by $\theta^{* *}=\frac{\beta_{1}-\beta_{0}}{1-\beta_{1}}$.

3. The mixed strategy equilibrium with mistrusted liquidation exists for $\beta_{1}^{\text {min }}<\beta_{1}<\underline{\beta}_{1}$. The threshold value is $\theta^{* * *}=\frac{1-\beta_{0}}{1-\beta_{1}}-\frac{u}{2 \beta_{1}+u+r}$.

\section{Proof See Appendix B.}

Proposition 1 shows that pure and mixed strategy equilibria exist for different values of $\beta_{1}$ and $\beta_{0}$. Figure 2 illustrates the different equilibrium regions for $u=0.4$ and $r=0.2$ and helps to explain the intuition behind the results.

The dashed line depicts the compensation in the case of no filtering failure $\beta_{1}^{*}=\beta_{0}+\frac{u-r}{2}$. No filtering failure is induced because $\beta_{1}^{*}$ exactly adjusts for the uncompensated continuation cost $u$ and non-monetary continuation benefits $r$. As long as the difference between $\beta_{1}$ and $\beta_{1}^{*}$ is not too large, a pure separating equilibrium with inefficient liquidation or continuation exists. If $\beta_{0}$ exceeds $1+\frac{3}{2}(r-u)=0.7$, the separating equilibrium with no filtering failure can no longer be implemented, as $\beta_{1}^{*}$ exceeds $\bar{\beta}_{1}$. Increasing $\beta_{1}$ beyond $\bar{\beta}_{1}$ creates stronger continuation incentives for the insolvency administrator. The creditors counterbalance these distorted incentives by stochastically accepting or rejecting the continuation proposal. Thus, the mixed strategy equilibrium with mistrusted

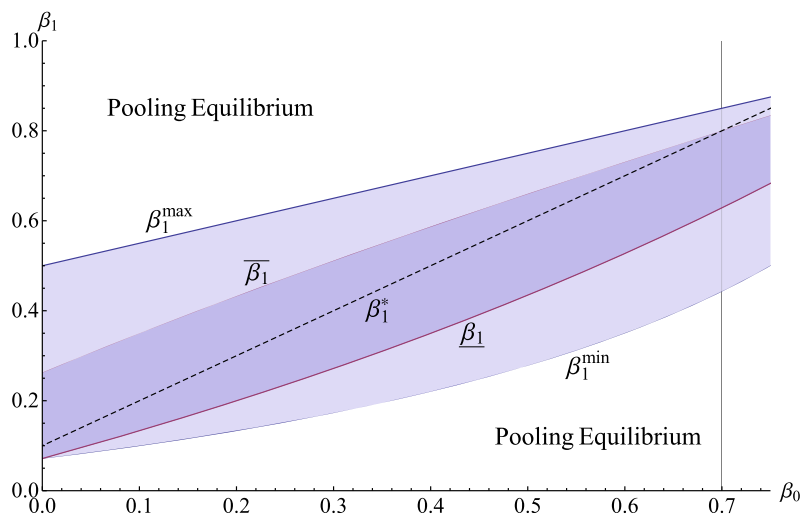

Fig. 2 Pure and mixed strategy equilibria depending on $\beta_{1}$ and $\beta_{0}$ for $u=0.4$ and $r=0.2$ 
continuation emerges. The opposite effect appears if $\beta_{1}$ falls below $\underline{\beta}_{1}$. In this case, liquidation incentives are relatively strong. As a consequence, the creditors do not always accept the liquidation proposal, implying the mixed strategy equilibrium with mistrusted liquidation.

Figure 3 displays the threshold values $\theta^{*}, \theta^{* *}$ and $\theta^{* * *}$ depending on $\beta_{1}$ in the pure and mixed strategy separating equilibria for different values of $\beta_{0}$ and $u=0.4$ and $r=0.2$.

We consider the pure strategy equilibrium ranges first. These ranges, given by the interval $\left(\beta_{1}\left(\beta_{0}\right), \bar{\beta}_{1}\left(\beta_{0}\right)\right)$, are shifted to the right with an increase in $\beta_{0}$. Moreover, the threshold value $\theta^{*}$ starts above the no filtering failure level $\theta^{*}=1 / 2$ at $\beta_{1}=$ $\underline{\beta}_{1}\left(\beta_{0}\right)$ and decreases in $\beta_{1}$ because a higher compensation for continuation should drive down the insolvency administrator's preferences for liquidation.

In both mixed strategy regions, however, the thresholds $\theta^{* *}$ and $\theta^{* * *}$ increase with $\beta_{1}$. Intuitively, one would expect decreasing thresholds similar to the pure strategy equilibrium. However, the increasing $\theta^{* *}$ and $\theta^{* * *}$ in $\beta_{1}$ are indeed a necessary property of the mixed strategy equilibrium. In both mixed strategy equilibria, the threshold value is determined such that the creditors are indifferent between liquidation and continuation upon receiving the insolvency administrator's liquidation (or continuation) proposal. A larger compensation $\beta_{1}$ does not affect the creditor's liquidation payoff. However, it reduces the creditors' expected profit, conditional on continuation. Shifting the threshold value to the right enhances the creditors' expected payoff and, thus, counterbalances the reduction caused by the increased compensation $\beta_{1}$.

In the following Proposition 2, we analyse the separating equilibria in a situation in which the non-monetary benefits exceed the uncompensated costs $(r>u)$.

Proposition 2 Suppose that $0<u<r$, and $0 \leq \beta_{0}<\frac{2-r+u}{4}+\sqrt{\frac{(r-u-2)^{2}}{16}+u(u-r)}$. Then, the compensation parameters $\beta_{0}$ and $\beta_{1}$ induce the following equilibria:

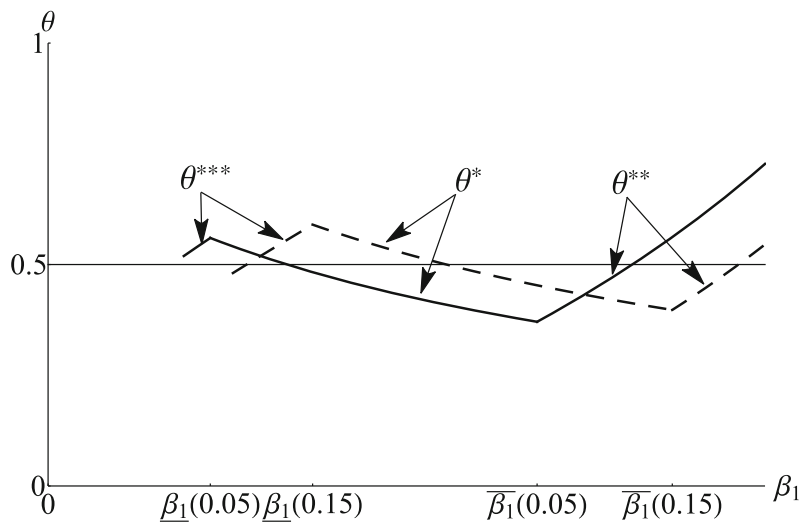

Fig. 3 Threshold values $\theta^{*}, \theta^{* *}$ and $\theta^{* * *}$ for $\beta_{0}=0.05$ (solid line); $\beta_{0}=0.15$ (dashed line) and $u=0.4$; $r=0.2$ depending on $\beta_{1}$ 
1. A pure strategy equilibrium with $\theta^{*}=\frac{\beta_{0}+u}{2 \beta_{1}+u+r}$ exists if $\beta_{1}$ and $\beta_{0}$ are such that $\underline{\beta}_{1} \leq \beta_{1} \leq \bar{\beta}_{1}$. The no filtering failure equilibrium $\theta^{*}=\frac{1}{2}$ is induced for $\beta_{1}^{*}=\beta_{0}+\frac{u-r}{2} \in\left(\underline{\beta}_{1}, \bar{\beta}_{1}\right)$.

2. The mixed strategy equilibrium with mistrusted continuation emerges if $\bar{\beta}_{1}<\beta_{1}<\beta_{1}^{\max }$. The threshold value is given by $\theta^{* *}=\frac{\beta_{1}-\beta_{0}}{1-\beta_{1}}$.

3. The mixed strategy equilibrium with mistrusted liquidation exists for $\beta_{1}^{\text {min }}<\beta_{1}<\underline{\beta}_{1}$. The threshold value is $\theta^{* * *}=\frac{1-\beta_{0}}{1-\beta_{1}}-\frac{u}{2 \beta_{1}+u+r}$.

\section{Proof See Appendix C.}

Proposition 2 is similar to Proposition 1 above. The threshold values for the pure strategy equilibrium and mixed strategy equilibriums are the same. The only noticeable difference from the case with $u>r$ is the upper limit $\beta_{0}<\frac{2-r+u}{4}+\sqrt{\frac{(r-u-2)^{2}}{16}+u(u-r)}$. The upper limit ensures that a pure strategy separating equilibrium with no filtering failure can be implemented.

Similar to Fig. 2, Fig. 4 shows the equilibrium regions depending on $\beta_{1}$ and $\beta_{0}$. As above, the pure strategy equilibrium will be valid if $\beta_{1}$ moderately deviates from $\beta_{1}^{*}$. Moreover, the pure strategy equilibrium can exhibit inefficient liquidation or inefficient continuation. Increasing $\beta_{1}$ above the threshold value $\bar{\beta}_{1}$ induces the mixed strategy equilibrium with mistrusted continuation, and decreasing $\beta_{1}$ below $\underline{\beta}_{1}$ implements the mixed strategy equilibrium with mistrusted liquidation.

The compensation parameters $\beta_{0}$ and $\beta_{1}$ can be designed such that the game between the insolvency administrator and the creditor exhibits no inefficient liquidations and continuations, provided that the regulator has information concerning uncompensated costs and non-monetary benefits. However, the consequences for the satisfaction of the creditor's claims are thus far unclear and are analysed in the next section.

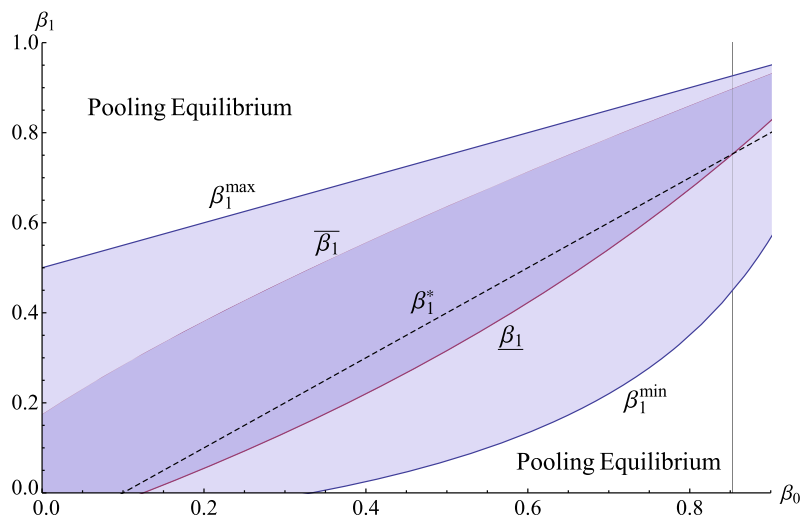

Fig. 4 Pure and mixed strategy equilibria depending on $\beta_{1}$ and $\beta_{0}$ for $u=0.2$ and $r=0.4$ 


\section{Creditor payoff and insolvency administrator compensation}

In the previous section, we analysed how the insolvency administrator's compensation influences the economic future of the insolvent firm. In this section, we characterize the optimal compensation parameters $\beta_{0}$ and $\beta_{1}$ from the creditors' perspective. We concentrate on creditors for the following reason: In many jurisdictions, the purpose of insolvency law is to provide an institutional setting for the satisfaction of the creditors' claims. Thus, the insolvency administrator can be seen as an agent of the creditors, and his compensation should be designed so that the creditors' satisfaction is maximized. Therefore, it is natural to analyse whether optimal creditor satisfaction and no filtering failure can be achieved simultaneously in our setting. We derive the expected creditor payoffs in the equilibria first:

- Mistrusted liquidation $\left(\beta_{1} \in\left(\beta_{1}^{\min }, \underline{\beta}_{1}\right)\right)$ : The firm will be liquidated for $\theta<\theta_{\mathrm{P}}$. Note that the threshold value $\theta^{* * *}$ is determined such that $\int_{\theta_{\mathrm{P}}}^{\theta^{* * *}}\left(1-\beta_{1}\right) 2 \theta \mathrm{d} \theta=\int_{\theta_{\mathrm{P}}}^{\theta^{* * *}}\left(1-\beta_{0}\right) \mathrm{d} \theta$. For $\theta>\theta^{* * *}$, the firm will be continued. Thus,

$$
\begin{aligned}
E\left[\Pi^{\mathrm{C}}\left(\beta_{0}, \beta_{1}\right)\right]= & \int_{0}^{\theta_{\mathrm{P}}}\left(1-\beta_{0}\right) \mathrm{d} \theta+\int_{\theta_{\mathrm{P}}}^{1}\left(1-\beta_{1}\right) 2 \theta \mathrm{d} \theta \\
& =\left(1-\beta_{0}\right) \theta_{\mathrm{P}}+\left(1-\beta_{1}\right)\left(1-\theta_{\mathrm{P}}{ }^{2}\right) .
\end{aligned}
$$

- Pure strategy equilibrium $\left(\beta_{1} \in\left[\underline{\beta}_{1}, \bar{\beta}_{1}\right)\right)$ : Liquidation appears for $\theta<\theta^{*}$ and continuation for $\theta \geq \theta^{*}$. Thus,

$$
\begin{aligned}
E\left[\Pi^{\mathrm{C}}\left(\beta_{0}, \beta_{1}\right)\right]= & \int_{0}^{\theta^{*}}\left(1-\beta_{0}\right) \mathrm{d} \theta+\int_{\theta^{*}}^{1}\left(1-\beta_{1}\right) 2 \theta \mathrm{d} \theta \\
& =\left(1-\beta_{0}\right) \theta^{*}+\left(1-\beta_{1}\right)\left(1-\theta^{* 2}\right) .
\end{aligned}
$$

- Mistrusted continuation $\left(\beta_{1} \in\left[\bar{\beta}_{1}, \beta_{1}^{\max }\right)\right)$ : The threshold value $\theta^{* *}$ is determined such that $\int_{\theta^{* *}}^{1}\left(1-\beta_{0}\right) \mathrm{d} \theta=\int_{\theta^{* *}}^{1}\left(1-\beta_{1}\right) 2 \theta \mathrm{d} \theta$. Thus,

$$
E\left[\Pi^{\mathrm{C}}\left(\beta_{0}, \beta_{1}\right)\right]=1-\beta_{0} .
$$

Proposition 3 defines the creditor's payoff-maximizing compensation parameters for $u>r$ :

Proposition 3 Suppose that $u>r$. Then $\hat{\beta}_{0}=0$ and $\hat{\beta}_{1}=\frac{u-r}{2(1+u)}$ maximize the creditor's payoff and imply a pure strategy equilibrium with $\theta^{*}=\frac{1+u}{(1+u)+(1+r)} \in\left(\frac{1}{2}, 1\right)$.

Proof See Appendix D.

The values $\beta_{0}^{*}$ and $\beta_{1}^{*}$, which avoid filtering failure, are intuitively appealing because the first-order effects of the compensation parameters on the creditors' payoff dominate. Liquidation causes no uncompensated costs, and thus, $\beta_{0}$ can be 
set equal to zero in the optimal compensation. The compensation for continuation has to be positive and is set such that the separating equilibrium is preserved.

Several properties of Proposition 3 will be highlighted in greater detail.

1. First, the payoff-maximizing $\hat{\beta}_{1}$ is below the efficiency-inducing $\beta_{1}^{*}$. Thus, maximizing the creditor's payoff implies $\theta^{*}>\frac{1}{2}$ and induces inefficient liquidation. Consequently, simultaneously maximizing the creditor's payoff and avoiding filtering failure is impossible. Only in case of $u=r$ optimal creditor satisfaction and no filtering failure can be achieved simultaneously. Efficiency losses appear for $u>r$ and rise in $u-r$, as the discrepancy between the no filtering failure threshold $\frac{1}{2}$ and $\frac{1+u}{(1+u)+(1+r)} \in\left(\frac{1}{2}, 1\right)$ increases.

2. To investigate the efficiency losses further, we analyse the distributional and welfare implications. That is, we compare the payoffs under optimal creditor satisfaction with a setting in which the creditor's payoff is maximized such that no efficiency losses (no filtering failure) are induced. The payoffs under no filtering failure ${ }^{4}$ are

$$
E\left[\tilde{\Pi}^{\mathrm{C}}\right]=\frac{5}{4}-\frac{3(u-r)}{8} \quad \text { and } \quad E\left[\tilde{\Pi}^{\mathrm{IA}}\right]=\frac{3(u-r)}{8} .
$$

Summing $E\left[\tilde{\Pi}^{\mathrm{C}}\right]$ and $E\left[\tilde{\Pi}^{\mathrm{IA}}\right]$ yields $\frac{5}{4}$. Inserting $\hat{\beta}_{0}$ and $\hat{\beta}_{1}$ yields the expected monetary (without $u$ ) payoffs under optimal creditor satisfaction as

$$
\begin{aligned}
& E\left[\Pi^{\mathrm{C}}\right]=1+\frac{1+r}{2(1+u)}-\frac{1+r}{(2+2 u)+(2+2 r)} \quad \text { and } \\
& E\left[\Pi^{\mathrm{IA}}\right]=\frac{(1+r)(u-r)(2 u+r+3)}{2(1+u)(2+r+u)^{2}}
\end{aligned}
$$

Summing up yields

$$
E\left[\Pi^{\mathrm{C}}\right]+E\left[\Pi^{\mathrm{IA}}\right]=1+\frac{1+r+u+r u}{(r+u+2)^{2}} \leq \frac{5}{4} .
$$

We proceed with $r>u$. Here, the creditor's payoffs are the same as in Proposition 2. Proposition 4 provides the optimal compensation from the creditor's perspective.

Proposition 4 Suppose that $u<r$. For $u>-\frac{1+r}{2}+\sqrt{\frac{(1+r)^{2}}{4}+r}$, the compensation parameters $\hat{\beta}_{1}=0$ and $\hat{\beta}_{0}=0$ maximize the creditor's payoff and imply a pure strategy equilibrium with $\theta^{*}=\frac{u}{u+r} \in\left(0, \frac{1}{2}\right)$. If $u<-\frac{1+r}{2}+\sqrt{\frac{(1+r)^{2}}{4}+r}$, the compensation parameters $\hat{\beta}_{1}=0$ and $\hat{\beta}_{0}=\frac{(1-u) r-u(1+u)}{2(1+r+u)}$ maximize the creditor's payoff and imply a pure strategy equilibrium with $\theta^{*}=\frac{1+u}{2(1+r+u)} \in\left(0, \frac{1}{2}\right)$.

Proof See Appendix E.

\footnotetext{
${ }^{4}$ The values $\beta_{0}=0$ and $\beta_{1}=\frac{u-r}{2}$ maximize the creditor's payoff and induce no filtering failure.
} 
The intuition behind the optimal compensation given in Proposition 4 is as follows: Because of the negative first-order effects of $\beta_{1}$ on the creditor's payoff, it is reasonable to set $\beta_{1}=0$. The optimal compensation $\beta_{0}$ depends on the difference between $u$ and $r$. For a small difference, it is reasonable to set $\beta_{0}=0$. For larger differences, $\beta_{0}=\frac{(1-u) r-u(1+u)}{2(1+r+u)}$ maximizes the creditor's payoff.

We observe properties similar to Proposition 3:

1. The compensation does not counterbalance the insolvency administrator's continuation bias, as the resulting threshold values $\theta^{*}=\frac{u}{u+r}$ and $\theta^{*}=\frac{1+u}{2(1+r+u)}$ are below $\frac{1}{2}$. Moreover, $\theta^{*}$ decreases in the discrepancy between $u$ and $r$, and thus, inefficient continuation appears more frequently when the insolvency administrator's continuation benefits increase.

2. We can compare the creditor's and the insolvency administrator's monetary payoffs under optimal creditor satisfaction and under no filtering failure. Given no filtering failure and therefore efficient liquidation and continuation, $\beta_{0}=\frac{r-u}{2}$ and $\beta_{1}=0$ maximize the creditor's payoff. We obtain

$$
E\left[\tilde{\Pi}^{\mathrm{C}}\right]=\frac{5}{4}-\frac{r-u}{4} \quad \text { and } \quad E\left[\tilde{\Pi}^{\mathrm{IA}}\right]=\frac{r-u}{4} .
$$

The total monetary payoff is $E\left[\tilde{\Pi}^{\mathrm{C}}\right]+E\left[\tilde{\Pi}^{\mathrm{IA}}\right]=\frac{5}{4}$, and no deadweight loss occurs. Optimal creditor satisfaction for $u>-\frac{1+r}{2}+\sqrt{\frac{(1+r)^{2}}{4}+r}$ yields the payoffs

$$
E\left[\Pi^{\mathrm{C}}\right]=1+\frac{r u}{(r+u)^{2}} \quad \text { and } \quad \mathrm{E}\left[\Pi^{\mathrm{IA}}\right]=0 .
$$

Summing $E\left[\Pi^{\mathrm{C}}\right]$ and $E\left[\Pi^{\mathrm{IA}}\right]$ yields $1+\frac{r u}{(r+u)^{2}} \leq \frac{5}{4}$. Inefficient liquidation and continuation induce a deadweight loss of $\frac{1}{4} \frac{(r-u)^{2}}{(r+u)^{2}}$.

If $u<-\frac{1+r}{2}+\sqrt{\frac{(1+r)^{2}}{4}+r}$, the optimal creditor satisfaction yields the payoffs

$$
E\left[\Pi^{\mathrm{C}}\right]=1+\frac{1+u(2+u)}{4(1+r+u)} \quad \text { and } \quad \mathrm{E}\left[\Pi^{\mathrm{IA}}\right]=\frac{(1+\mathrm{u})\left(\mathrm{r}(1-\mathrm{u})-\mathrm{u}^{2}-\mathrm{u}\right)}{4(1+\mathrm{r}+\mathrm{u})^{2}} \text {. }
$$

Summing both payoffs yields

$$
E\left[\Pi^{\mathrm{C}}\right]+E\left[\Pi^{\mathrm{IA}}\right]=\frac{5}{4}-\frac{r^{2}}{4(r+u+1)^{2}} \leq \frac{5}{4} .
$$

Inefficient liquidation and continuation induce a deadweight loss of $\frac{r^{2}}{4(r+u+1)^{2}}$

We further investigate the findings of Propositions 3 and 4 in a numerical example. Figures 5 and 6 display the creditor's and insolvency administrator's expected monetary payoff with respect to $u$ for the optimal creditor satisfaction and the no filtering failure scenario. The dashed lines represent the no filtering failure regime, and the solid lines the payoffs under optimal creditor satisfaction. Both under 
Fig. 5 Expected creditor payoff under no filtering failure (dashed line) and optimal creditor satisfaction $\hat{\beta}_{0}$ and $\hat{\beta_{1}}$ (solid line) for $u=0$..0.4 and $r=0.2$

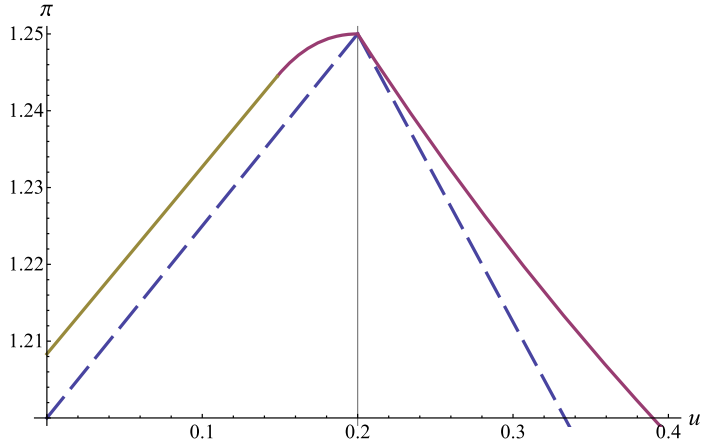

Fig. 6 Expected monetary insolvency administrator payoff (without $u$ and $r$ ) under no filtering failure (dashed line) and optimal creditor satisfaction $\hat{\beta}_{0}$ and $\hat{\beta_{1}}$ (solid line) for $u=$ $0 . .0 .4$ and $r=0.2$

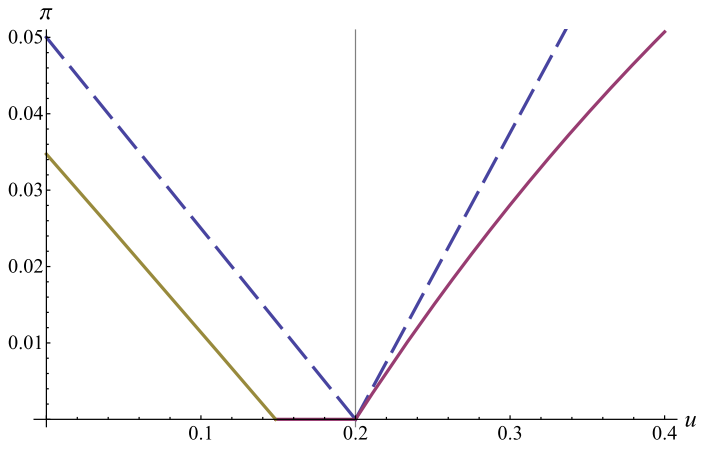

optimal creditor satisfaction and no filtering failure, the expected creditor payoff in Fig. 5 decreases in a higher discrepancy between $u$ and $r$, as the insolvency administrator must obtain a larger share of the pie. This observation is reflected in Fig. 6, where the insolvency administrator's (gross) payoff increases in the discrepancy between $u$ and $r$. For $u>r$, this result is due to his uncompensated costs. In the case of $u<r$, the insolvency administrator does not earn any rent as long the discrepancy is not too large. For higher differences, he has to earn a rent to make liquidation sufficiently attractive.

In Fig. 7, the total monetary payoffs under the two regimes are compared. The efficiency loss is given by the difference between the dashed and the solid curve. Unsurprisingly, the efficiency loss increases in the discrepancy between $u$ and $r$.

Finally, we consider the insolvency administrator's net payoff $E\left[\Pi_{\text {net }}^{\mathrm{IA}}\right]=$ $\int_{0}^{\theta^{*}} \beta_{0} f(\theta) \mathrm{d} \theta+\int_{\theta^{*}}^{1}\left(\beta_{1} \theta-(1-\theta) u+\theta r\right) f(\theta) \mathrm{d} \theta=\theta^{*} \beta_{0}-\left(1-\theta^{*}\right) u+\frac{\left(1-\theta^{* 2}\right)}{2}\left(\beta_{1}+\right.$ $u+r)$ depicted in Fig. 8. The net payoff will be larger for $u<r$, as in this case, the insolvency administrator has reputational benefits from continuing the insolvent firm.

Motivated by the insolvency administrator compensation observed in Germany and several other European countries, our setting was restricted to a linear contract based on the liquidation and continuing value so far. In the following, we look how the results change when the continuation value is the insolvency administrator's 
Fig. 7 Expected total monetary payoff under no filtering failure (dashed line) and optimal creditor satisfaction $\hat{\beta}_{0}$ and $\hat{\beta_{1}}$ (solid line) for $u=0 \ldots .4$ and $r=0.2$

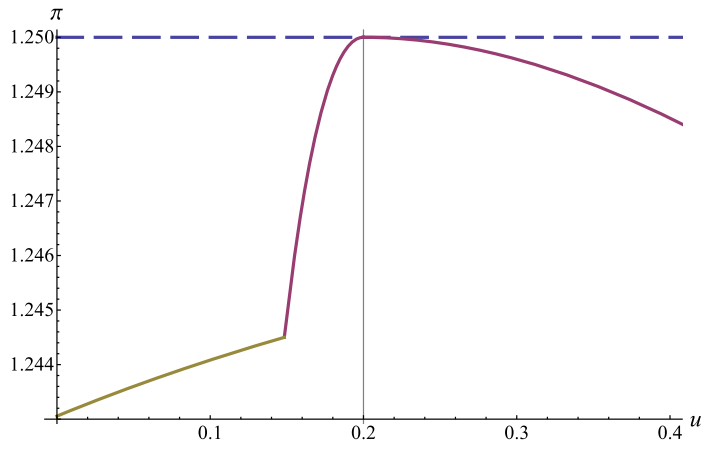

Fig. 8 Expected total insolvency administrator payoff (net of $u$ ) under efficient compensation (dashed line) and optimal creditor satisfaction $\hat{\beta}_{0}$ and $\hat{\beta_{1}}$ (solid line) for $u=$ Oldots 0.4 and $r=0.2$

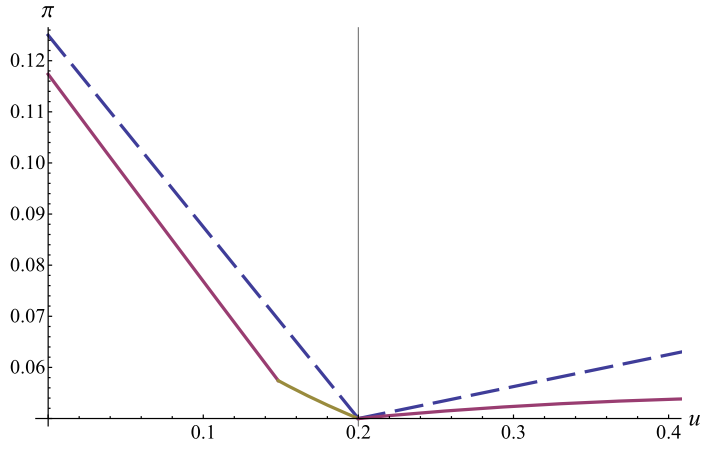

private information and, thus, not contractible. Therefore, the compensation is restricted to fixed payments conditional on liquidation $\left(b_{0}\right)$ and continuation $\left(b_{1}\right)$. Table 1 in Appendix A shows that fixed payments as insolvency administrator compensation are also common in several European insolvency codes.

As above, we analyse the optimal compensation from the creditor's perspective and the resulting filtering failure. To be short, we restrict our analysis to the pure strategy equilibrium and skip the mixed strategy equilibria. In the pure strategy case, the outcome will be liquidation whenever $b_{0}>b_{1}-u+\theta(r+u)$. It can be seen that liquidation is preferred for low values of $\theta$. The insolvency administrator is indifferent between the two alternatives if

$$
b_{0}=b_{1}-u+\theta^{*}(r+u) \Leftrightarrow \theta^{*}=\frac{b_{0}-b_{1}+u}{r+u} .
$$

Inserting into the expected creditor's payoff yields

$$
E\left(\Pi^{\mathrm{C}}\left(b_{0}, b_{1}\right)\right)=\theta^{*}\left(1-b_{0}\right)+\left(1-\theta^{* 2}\right)-\left(1-\theta^{*}\right) b_{1} .
$$

The partial derivatives are

$$
\frac{\partial E\left(\Pi^{\mathrm{C}}\right)}{\partial b_{0}}=\frac{1}{u+r}\left(1-b_{0}+b_{1}-2 \theta^{*}\right)-\theta^{*}
$$

and 


$$
\frac{\partial E\left(\Pi^{\mathrm{C}}\right)}{\partial b_{1}}=-\frac{1}{u+r}\left(1-b_{0}+b_{1}-2 \theta^{*}\right)-\left(1-\theta^{*}\right)=-\frac{\partial E\left(\Pi^{\mathrm{C}}\right)}{\partial b_{0}}-1 .
$$

From (18) and (19), it can be seen that $b_{0}^{*}>0 \Rightarrow b_{1}^{*}=0$ and $b_{0}^{*}=0 \Rightarrow b_{1}^{*} \geq 0$. Proposition 5 demonstrates the details:

Proposition 5 In a pure strategy equilibrium, the following fixed compensation payments maximize the creditor's payoff:

1. Suppose $u<-\frac{1+r}{2}+\sqrt{\frac{(1+r)^{2}}{4}+r}$. Then $\quad \hat{b}_{1}=0, \quad \hat{b}_{0}=\frac{(1-u) r-u(1+u)}{2(u+r+1)} \quad$ and $\theta^{*}=\frac{1+u}{2(u+r+1)}$.

2. In the case of $-\frac{1+r}{2}+\sqrt{\frac{(1+r)^{2}}{4}+r}<u<\frac{1+r}{1-r} r, \hat{b}_{0}=\hat{b}_{1}=0$ and $\theta^{*}=\frac{u}{r+u}$.

3. If $u>\frac{1+r}{1-r} r, \hat{b}_{0}=0, \hat{b}_{1}=\frac{(1-r) u-r(1+r)}{2(u+r+1)}$ and $\theta^{*}=\frac{r+2 u+1}{2(u+r+1)}$.

Proof See Appendix F.

Proposition 5 shows that maximizing the creditor's payoff through fixed payments will also induce filtering failure, except for $u=r$. Basically, we observe similar results as under linear contracts. For $u \leq r$, optimal fixed compensation exactly resembles Proposition 4 . This observation is due to the fixed compensation $\hat{\beta}_{1}=\hat{b}_{1}=0$ in both cases. Since $\frac{u}{u+r}>\frac{1}{2}$ and $\frac{r+2 u+1}{2(u+r+1)}>\frac{1}{2}$, we also obtain a liquidation bias if $u>r$. However, the threshold values and also the expected payoff to the creditors differ. Corollary 1 shows the details.

Corollary 1 Suppose $u>r$ and insolvency administrator compensation according to Propositions 3 and 5. Then, the resulting threshold value $\theta^{*}$ and the expected creditor payoff is larger under fixed compensation than under linear compensation.

Proof See Appendix G.

Under a fixed compensation scheme, the insolvency administrator's liquidation incentives are stronger and filtering failure occurs more often. Moreover, the creditor would prefer fixed over linear compensation, which is quite intuitive: Linear compensation induces high compensation in cases where non-monetary benefits to the insolvency administrator are large. Overall, the linear scheme is based on more information than fixed compensation, but from the creditor's perspective, it does not make use of it in an optimal way.

This situation changes if continuation and liquidation values are verifiable and contractible and contract design is not restricted. In this case, a simple compensation scheme exists that extracts the insolvency administrator's expected rents in the limit and induces no filtering failure at the same time. This scheme is given by a zero fixed payment upon liquidation $\left(\beta_{0}=0\right)$, and a combination of fixed and variable payments conditional on the continuing value $C V(\theta, \varepsilon)=2 \theta+\varepsilon$ written as $B^{\mathrm{tb}}+$ $\beta_{1}^{\mathrm{fb}} C V(\theta, \varepsilon)$ in the case of continuation. The fixed payment is $B^{\mathrm{fb}}=u-\eta E_{\varepsilon}[C V(\theta=$ $\left.\left.\frac{1}{2}\right)\right]=u-\eta$ and $\beta_{1}^{\mathrm{fb}}=\eta-\frac{(r+u)}{2}$. The parameter $\eta$ captures a sufficiently small 
positive (negative) payment in the case of continuation for $\theta>\frac{1}{2}\left(\theta<\frac{1}{2}\right)$. It can be seen that the insolvency administrators' payoff, including uncompensated costs and benefits, boils down to

$$
u-\eta+\left(\eta-\frac{r+u}{2}\right) \cdot 2 \theta-u+(u+r) \theta=\eta(2 \theta-1) .
$$

If $\lim _{\eta \rightarrow 0} \eta(2 \theta-1)=0$ and $\eta(2 \theta-1) \geq 0 \Leftrightarrow \theta \geq \frac{1}{2}$ as long as $\eta>0$. Of course, this scheme works because of the risk neutrality and unlimited liability of both parties. Moreover, the insolvency administrator's preferences represented by $u$ and $r$ have to be observable and a verifiable and unbiased estimator of the continuation value must be available.

The scheme presented above shows that optimal creditor satisfaction and no filtering failure can be achieved simultaneously if the creditor and the insolvency administrator individually negotiate the compensation contract without any legislative constraints. However, a first best compensation scheme will generally not be implementable by regulation because insolvency administrators differ with respect to unverifiable uncompensated costs and benefits. Therefore, a presumably more promising way to improve insolvency proceedings with respect to the conflict of interest between creditors and insolvency administrator would be to control uncompensated costs and benefits. We discuss this point in Sect. 6.

In summary, the results in this section are comparable to the second best outcome of typical principal-agent problems. From this perspective, the interaction between a creditor and an insolvency administrator can be seen as a setting in which the principal hires an agent with different objectives and private information. The creditor finds it too expensive to select a compensation for the insolvency administrator that induces first best actions. The tension vanishes only if conflicts of interest due to uncompensated costs and non-monetary benefits disappear.

\section{Implications}

The essential result in the preceding two sections states that insolvency procedures coordinated by a better-informed insolvency administrator will never simultaneously achieve optimal creditor satisfaction and no filtering failure if the insolvency administrator's compensation is designed as typical in many insolvency codes. The driving force behind this result is a conflict of interest between the creditor and the better-informed insolvency administrator that originates from uncompensated costs and non-monetary benefits. As discussed in the model description above, these typically represent liability risks and non-monetary benefits, such as building a valuable reputation from reorganizing and continuing the insolvent firm.

For example, liability risk arises because many decisions with a highly uncertain future outcome must be made during the continuation. As a party with deep pockets, creditors may sue the insolvency administrator for damage payments after an unsuccessful reorganization, even if the administrator's decision was reasonable at the time it was made. Moreover, public attitude may claim higher liabilities for the 
insolvency administrator after a publicly observable continuation with bad outcomes. The results of our paper imply that stronger liability regimes may be counter-productive for overall welfare and the creditors' payoff if higher liability risks are not compensated by non-monetary benefits. Compensating higher liability risk with increased monetary compensation in the event of a continuation may induce efficient decisions at the cost of the creditor's payoff.

The most important example of non-monetary benefits for an insolvency administrator is reputational issues. Regulation has had a strong impact on the value of reputation, as the following example shows. In 2011, the German government implemented an insolvency law reform intended to encourage the reorganization of insolvent firms. ${ }^{5}$ Prior to the reform, the insolvency court assigned an insolvency administrator to the insolvent firm. The court had to choose the insolvency administrator from a list and thus had considerable leeway. Ultimately, this process was rather obscure. Under the new law, the creditor can decide which insolvency administrator to choose. ${ }^{6}$ The reform will clearly change the value of reputation in the event of a continuation decision. Insolvency judges might have preferences for a reorganization of the insolvent firm because of negative public reactions to a liquidation. Thus, they select insolvency administrators with a strong record of reorganization. Creditors concentrate on the satisfaction of their claim and prefer an insolvency administrator with a history of high insolvency dividends. Therefore, the non-monetary benefit of a reorganization might have declined due to the reform.

\section{Conclusion}

This paper discusses the impact of the insolvency administrator on ex post efficiency and creditor satisfaction in bankruptcy procedures. We incorporate asymmetric information and incongruent objectives between a creditor and an insolvency administrator into a sequential game. Our key result states that the remuneration schemes typically used in insolvency proceedings will not allow a compensation of the insolvency administrator that simultaneously avoids any filtering failure and provides optimal creditor satisfaction. Optimal creditor satisfaction will always imply false liquidation or continuation decisions due to uncompensated costs or non-monetary benefits. The theory in this paper adds to the literature a novel explanation for the emergence of filtering failure in insolvency proceedings.

Open Access This article is distributed under the terms of the Creative Commons Attribution 4.0 International License (http://creativecommons.org/licenses/by/4.0/), which permits unrestricted use, distribution, and reproduction in any medium, provided you give appropriate credit to the original author(s) and the source, provide a link to the Creative Commons license, and indicate if changes were made.

\footnotetext{
5 "Gesetz zur weiteren Erleichterung der Sanierung von Unternehmen" (ESUG).

${ }^{6}$ cf. Section 56a InsO.
} 


\section{Appendix A: Characteristics of International Insolvency Procedures}

In all selected insolvency procedures, an administrator can influence the output of an insolvency. We excluded procedures where the result is fixed at the time of filing for insolvency. The evaluation is based on the different insolvency codes. ${ }^{7}$

\section{Appendix B: Proof of Proposition 1}

Pure strategy equilibrium We start the proof with the pure strategy equilibrium. Given the creditor's equilibrium behaviour, the insolvency administrator (henceforth, IA) is better off under a continuation proposal if

$$
\beta_{0} \leq 2 \beta_{1} \theta-(1-\theta) u+\theta r \Leftrightarrow \theta \geq \frac{\beta_{0}+u}{2 \beta_{1}+u+r}=: \theta^{*} .
$$

The creditor will accept the proposal if the following two conditions hold:

1. The creditor will follow the continuation proposal if

$$
\int_{\theta^{*}}^{1}\left(1-\beta_{0}\right) \frac{f(\theta)}{\left(1-F\left(\theta^{*}\right)\right)} \mathrm{d} \theta \leq \int_{\theta^{*}}^{1}\left(1-\beta_{1}\right) 2 \theta \frac{f(\theta)}{\left(1-F\left(\theta^{*}\right)\right)} \mathrm{d} \theta
$$

holds. Reformulating yields

$$
\theta^{*}=\frac{\beta_{0}+u}{2 \beta_{1}+u+r} \geq \frac{\beta_{1}-\beta_{0}}{1-\beta_{1}} .
$$

The critical value $\bar{\beta}_{1}$ can be obtained by solving $\frac{\beta_{0}+u}{2 \bar{\beta}_{1}+u+r}=\frac{\bar{\beta}_{1}-\beta_{0}}{1-\bar{\beta}_{1}}$. The relevant solution is given by

$$
\bar{\beta}_{1}=\frac{\beta_{0}-2 u-r}{4}+\sqrt{\frac{\left(\beta_{0}-2 u-r\right)^{2}}{16}+\frac{\beta_{0}(1+u+r)+u}{2}} .
$$

Straightforward algebra shows that the condition $\bar{\beta}_{1}>\beta_{1}^{*}=\beta_{0}+\frac{u-r}{2}$ is equivalent to $\beta_{0}<1+\frac{3}{2}(r-u)$, which holds by assumption.

2. The creditor accepts the IA's liquidation proposal if

$$
\int_{0}^{\theta_{p}}\left(1-\beta_{0}\right) \frac{f(\theta)}{F\left(\theta^{*}\right)} \mathrm{d} \theta+\int_{\theta_{p}}^{\theta^{*}}\left(1-\beta_{1}\right) 2 \theta \frac{f(\theta)}{F\left(\theta^{*}\right)} \mathrm{d} \theta \leq \int_{0}^{\theta^{*}}\left(1-\beta_{0}\right) \frac{f(\theta)}{F\left(\theta^{*}\right)} \mathrm{d} \theta
$$

holds. For $\theta<\theta_{\mathrm{p}}$, the IA is unwilling to continue the insolvent firm; thus, $\theta_{\mathrm{p}}$ is defined by $2 \beta_{1} \theta_{\mathrm{P}}-\left(1-\theta_{\mathrm{P}}\right) u+\theta_{\mathrm{P}} r=0 \Leftrightarrow \theta_{\mathrm{p}}=\frac{u}{2 \beta_{1}+u+r}$. $\theta_{\mathrm{P}}>0$ is satisfied for all $u>0$. Reformulating yields

$$
\theta^{*}=\frac{\beta_{0}+u}{2 \beta_{1}+u+r} \leq \frac{1-\beta_{0}}{1-\beta_{1}}-\theta_{\mathrm{P}}
$$

\footnotetext{
${ }^{7}$ For the Hungarian Insolvency Code, see Franks and Loranth (2013).
} 
The critical value $\underline{\beta}_{1}$ can be obtained by solving $\frac{\beta_{0}+u}{2 \underline{\beta}_{1}+u+r}=\frac{1-\beta_{0}}{1-\underline{\beta}_{1}}-\theta_{P}$. The relevant solution is given by

$$
\underline{\beta}_{1}=\frac{\beta_{0}(1+r+u)+u-r}{2+2 u-\beta_{0}} .
$$

Condition $\underline{\beta}_{1}<\beta_{1}^{*}$ is equivalent to $\beta_{0}<\frac{2-r+u}{4}+\sqrt{\frac{(r-u-2)^{2}}{16}+u(u-r)}$. We can show that $\beta_{0}<\frac{2-r+u}{4}+\sqrt{\frac{(r-u-2)^{2}}{16}+u(u-r)}$ is dominated by $\beta_{0}<1+\frac{3}{2}(r-u)$ for all $u>r$, because both conditions are equal to $\beta_{0}<1$ for $u=r$. Taking the partial derivatives of $\beta_{0}<\frac{2-r+u}{4}+\sqrt{\frac{(r-u-2)^{2}}{16}+u(u-r)}$ yields $\frac{\mathrm{d} \beta_{0}}{\mathrm{~d} u}>0 ; \frac{\mathrm{d} \beta_{0}}{d r}<0$ for all values of $u>r$. In contrast, the partial derivatives of $\beta_{0}<1+\frac{3}{2}(r-u)$ yields $\frac{\mathrm{d} \beta_{0}}{\mathrm{~d} u}<0 ; \frac{\mathrm{d} \beta_{0}}{\mathrm{~d} r}>0$. Thus, $\beta_{0}<1+\frac{3}{2}(r-u)$ dominates for all $u>r$.

Finally, it remains to show that $\theta^{*}<1$ is satisfied for all admissible $\beta_{1}$. As $\theta^{*}<1 \Leftrightarrow \beta_{1}>\frac{\beta_{0}-r}{2}$, inequality

$$
\underline{\beta}_{1}>\frac{\beta_{0}-r}{2}
$$

implies our claim. Inserting $\beta_{1}$ and rearranging yield $\beta_{0} r+2 u>-\beta_{0}^{2}-2 u r$, which is true for $\beta_{0} \in(0,1)$ and $u, r>0$.

Mixed strategy equilibrium with mistrusted continuation First, the equilibrium threshold value $\theta^{* *}$ is set such that the creditors are indifferent between accepting and rejecting the IA's continuation proposal. From

$$
\int_{\theta^{* *}}^{1}\left(1-\beta_{0}\right) \frac{f(\theta)}{\left(1-F\left(\theta^{* *}\right)\right)} \mathrm{d} \theta=\int_{\theta^{* *}}^{1}\left(1-\beta_{1}\right) 2 \theta \frac{f(\theta)}{\left(1-F\left(\theta^{* *}\right)\right)} \mathrm{d} \theta
$$

we obtain

$$
\theta^{* *}=\frac{\beta_{1}-\beta_{0}}{1-\beta_{1}} .
$$

Second, the equilibrium probability $p^{r}$ ensures that the IA strictly prefers a liquidation (continuation) proposal for $\theta<(>) \theta^{* *}$ and is indifferent between the two alternatives at $\theta=\theta^{* *}$, which yields

$$
\begin{gathered}
\beta_{0}=\left(1-p^{r}\right)\left(\beta_{0}-K\right)+p^{r}\left(2 \beta_{1} \theta^{* *}-\left(1-\theta^{* *}\right) u+\theta^{* *} r\right) \\
\Leftrightarrow p^{r}=\frac{K}{K-u+\theta^{* *}(r+u)-\beta_{0}+2 \beta_{1} \theta^{* *}} .
\end{gathered}
$$

Apparently, $K>0$ ensures $p^{r}>0$ and $\frac{\mathrm{d} \theta_{1}^{* *}}{\mathrm{~d} \beta_{1}}>0$ implies $\theta^{* *}>\frac{u+\beta_{0}}{2 \beta_{1}+u+r}$, inducing $p^{r}<1 \forall \beta_{1}>\bar{\beta}_{1}$.

The condition $\theta^{* *}<1$ yields $\beta_{1}<\frac{1+\beta_{0}}{2}:=\beta_{1}^{\max }$. Moreover, simple algebra shows that the interval $\left(\bar{\beta}_{1}, \beta_{1}^{\max }\right)$ is non-empty for $\beta_{0}<1$. 
Mixed strategy equilibrium with mistrusted liquidation The threshold value is obtained from

$$
\int_{0}^{\theta_{p}}\left(1-\beta_{0}\right) \frac{f(\theta)}{F\left(\theta^{* * *}\right)} \mathrm{d} \theta+\int_{\theta_{\mathrm{p}}}^{\theta^{* * *}}\left(1-\beta_{1}\right) 2 \theta \frac{f(\theta)}{F\left(\theta^{* * *}\right)} \mathrm{d} \theta=\int_{0}^{\theta^{* * *}}\left(1-\beta_{0}\right) \frac{f(\theta)}{F\left(\theta^{* * *}\right)} \mathrm{d} \theta .
$$

Rearranging yields

$$
\theta^{* * *}=\frac{1-\beta_{0}}{1-\beta_{1}}-\theta_{\mathrm{P}}
$$

To be valid, $\theta^{* * *}=\frac{1-\beta_{0}}{1-\beta_{1}}-\theta_{P}>\theta_{\mathrm{P}}$ has to be satisfied. Rearranging this claim yields a lower bound $\beta_{1}>\frac{\beta_{0}(r+u)-r+u}{2\left(1-\beta_{0}+u\right)}:=\beta_{1}^{\text {min }}$.

The probability $p^{l}$ can be obtained by equating

$$
\begin{gathered}
p^{l} \beta_{0}+\left(1-p^{l}\right)\left(2 \beta_{1} \theta^{* * *}-\left(1-\theta^{* * *}\right) u+\theta^{* * *} r-K\right)=2 \beta_{1} \theta^{* * *}-\left(1-\theta^{* * *}\right) u+\theta^{* * *} r \\
\Leftrightarrow p^{l}=\frac{K}{K+u-\theta^{* * *}(r+u)+\beta_{0}-2 \beta_{1} \theta^{* * *}} .
\end{gathered}
$$

Again, $K>0$ and $\frac{d \theta_{1}^{* * *}}{d \beta_{1}}>0$ ensure $p^{l} \in(0,1)$.

To ensure the existence of the claimed equilibrium, $\beta_{1}^{\min }<\underline{\beta}_{1}$ has to be established, which is true for $\beta_{0} \in(0,1)$.

\section{Appendix C: Proof of Proposition 2}

Pure strategy equilibrium The pure strategy equilibrium can generally be derived as in Proposition 1 . The threshold value $\theta^{*}, \overline{\beta_{1}}$ and $\underline{\beta_{1}}$ are the same.

We have to check $\underline{\beta_{1}}<\beta_{1}^{*}$ and $\overline{\beta_{1}}>\beta_{1}^{*}$. Straightforward algebra shows that the condition $\underline{\beta_{1}}<\beta_{1}^{*}$ is equivalent to $\beta_{0}<\frac{2-r+u}{4}+\sqrt{\frac{(2-r+u)^{2}}{16}+u(u-r)}$, which holds by assumption. Condition $\overline{\beta_{1}}>\beta_{1}^{*}$, equivalent to $\beta_{0}<1+\frac{3}{2}(r-u)$, is dominated by the former condition because $1+\frac{3}{2}(r-u)>1-\frac{r-u}{2}=\frac{2-r+u}{2}=$ $\frac{2-r+u}{4}+\sqrt{\frac{(2-r+u)^{2}}{16}}>\frac{2-r+u}{4}+\sqrt{\frac{(2-r+u)^{2}}{16}+u(u-r)} \forall r>u$.

Mixed strategy equilibrium with mistrusted continuation The proof for the mixed strategy equilibrium with mistrusted continuation is exactly as in Proposition 1.

Mixed strategy equilibrium with mistrusted liquidation The proof for the mixed strategy equilibrium with mistrusted continuation is exactly as in Proposition 1. 


\section{Appendix D: Proof of Proposition 3}

The proof consists of two steps: First, we show that $\beta_{0}=0$ and $\beta_{1}=\frac{u-r}{2(1+u)}$ maximize the creditor's payoff in the pure strategy equilibrium. In the second step, we argue that the creditor's payoff will never be larger in one of the mixed strategy equilibria.

Step 1: The creditor's payoff in the pure strategy equilibrium is given by

$$
E\left[\Pi^{\mathrm{C}}\left(\beta_{0}, \beta_{1}\right)\right]=\left(1-\beta_{0}\right) \theta^{*}+\left(1-\beta_{1}\right)\left(1-\theta^{* 2}\right) .
$$

Taking the partial derivatives with respect to $\beta_{0}$ yields

$$
\frac{\partial E\left[\Pi^{\mathrm{C}}\right]}{\partial \beta_{0}}=\frac{\partial \theta^{*}}{\partial \beta_{0}}\left(1-\beta_{0}-\frac{\left(1-\beta_{1}\right) 2\left(\beta_{0}+u\right)}{2 \beta_{1}+r+u}\right)-\theta^{*}
$$

and

$$
\frac{\partial E\left[\Pi^{\mathrm{C}}\right]}{\partial \beta_{1}}=\frac{\partial \theta^{*}}{\partial \beta_{1}}\left(1-\beta_{0}-\frac{\left(1-\beta_{1}\right) 2\left(\beta_{0}+u\right)}{2 \beta_{1}+r+u}\right)-\left(1-\theta^{* 2}\right) .
$$

A sufficient condition for $\frac{\partial E\left[\Pi^{\mathrm{C}}\right]}{\partial \beta_{1}}<0$ can be obtained from

$$
\begin{gathered}
1-\beta_{0}-\frac{\left(1-\beta_{1}\right) 2\left(\beta_{0}+u\right)}{2 \beta_{1}+r+u}>0 \Leftrightarrow \\
\beta_{1}>\frac{2 \beta_{0}+u-r+\beta_{0}(u+r)}{2(1+u)}=\frac{\beta_{1}^{*}}{(1+u)}+\frac{\beta_{0}(u+r)}{2(1+u)} .
\end{gathered}
$$

Inserting $\beta_{1}^{*}=\beta_{1}$ into $\beta_{1}^{*}>\frac{\beta_{1}^{*}}{(1+u)}+\frac{\beta_{0}(u+r)}{2(1+u)} \Rightarrow u>-\beta_{0}$. Thus, the creditor's payoff will be maximal for $\beta_{1}<\frac{\beta_{1}^{*}}{(1+u)}+\frac{\beta_{0}(u+r)}{2(1+u)}<\beta_{1}^{*}$. Now consider $\frac{\partial E\left[\Pi^{\mathrm{C}}\right]}{\partial \beta_{0}}$ :

$$
\frac{\partial E\left[\Pi^{\mathrm{C}}\right]}{\partial \beta_{0}}<0 \Leftrightarrow \beta_{1}<\frac{\left(2 \beta_{0}+u\right)(1+u+r)-r}{2\left(1-\beta_{0}\right)}=\frac{\beta_{1}^{*}}{1-\beta_{0}}+\frac{\left(2 \beta_{0}+u\right)(u+r)}{2\left(1-\beta_{0}\right)} .
$$

Thus, $\beta_{1}<\beta_{1}^{*}$ implies that $\beta_{0}=0$ will be optimal. We conclude that the optimal compensation in a pure strategy equilibrium consists of $\beta_{1}<\beta_{1}^{*}$ and $\beta_{0}=0$. Inserting $\beta_{0}=0$ into $\frac{\partial E\left[\Pi^{\mathrm{C}}\right]}{\partial \beta_{1}}$ and $\underline{\beta_{1}}$ shows that $\frac{\partial E\left[\Pi^{\mathrm{C}}\right]}{\partial \beta_{1}}<0$ holds in the whole interval $\beta_{1} \in\left[\beta_{1}, \bar{\beta}_{1}\right)$. Thus, the optimal compensation in the pure strategy equilibrium is given by $\beta_{0}=0$ and $\beta_{1}=\frac{u-r}{2(1+u)}$. The creditor's payoff amounts to

$$
E\left[\Pi^{\mathrm{C}}\left(\beta_{0}=0, \beta_{1}=\frac{u-r}{2(1+u)}\right)\right]=1+\frac{1+r}{2+2 u}-\frac{1+r}{(2+2 u)+(2+2 r)}>1 \forall u, r .
$$


Step 2 It remains to show that the creditor's payoff will not be larger in one of the two mixed strategy equilibria. It is easy to rule out $\beta_{1}>\bar{\beta}_{1}$ : In this case, the payoff $\left(1-\beta_{0}\right)$ is maximized at $\beta_{0}=0$ but smaller than $1+\frac{1+r}{2+2 u}-\frac{1+r}{(2+2 u)+(2+2 r)}$.

We also have to rule out the mixed strategy equilibrium with mistrusted liquidation, which may arise for $\beta_{0}>0$ and $\beta_{1} \in\left[\frac{\beta_{0}(r+u)+u-r}{2+2 u-\beta_{0}}, \frac{\beta_{0}(1+r+u)+u-r}{2+2 u-\beta_{0}}\right)$. First, note that the interval is empty for $\beta_{0}=0$, as the upper and lower bounds are equal in this case. Second,

$$
\frac{\partial E\left[\Pi^{\mathrm{C}}\right]}{\partial \beta_{0}}=-\theta_{P}<0 .
$$

Third, the partial derivation with respect to $\beta_{1}$ yields

$$
\frac{\partial E\left[\Pi^{\mathrm{C}}\right]}{\partial \beta_{1}}=\frac{\partial \theta_{P}}{\partial \beta_{1}}\left(1-\beta_{0}-\frac{\left(1-\beta_{1}\right) 2 u}{2 \beta_{1}+u+r}\right)-\left(1-\theta_{P}^{2}\right) .
$$

A sufficient condition for $\frac{\partial E\left[\Pi^{\mathrm{C}}\right]}{\partial \beta_{1}}<0$ can be obtained from

$$
1-\beta_{0}-\frac{\left(1-\beta_{1}\right) 2 u}{2 \beta_{1}+u+r}>0 \Leftrightarrow \beta_{1}>\frac{\beta_{0}(r+u)-r+u}{2\left(-\beta_{0}+u+1\right)} .
$$

Condition (43) is most strict at $\beta_{1}=\beta_{1}^{\min }=\frac{\beta_{0}(r+u)+u-r}{2+2 u-\beta_{0}}$. Inserting $\beta_{1}^{\text {min }}$ into $\frac{\partial E\left[\Pi^{\mathrm{C}}\right]}{\partial \beta_{1}}$ shows that $\frac{\partial E\left[\Pi^{\mathrm{C}}\right]}{\partial \beta_{1}}=-\frac{(r+1)(r+2 u+3)}{(r+u+2)^{2}}<0$ holds in the whole interval $\beta_{1} \in\left[\beta_{1}^{\min }, \underline{\beta}_{1}\right)$.

Thus, the optimal compensation in the mixed strategy equilibrium is given by $\beta_{1}=\beta_{1}^{\min }=\frac{\beta_{0}(r+u)+u-r}{2+2 u-\beta_{0}}$ and $\beta_{0}=\xi$. The creditor's payoff maximizes if $\xi \rightarrow 0$ and amounts to

$$
E\left[\Pi^{\mathrm{C}}\right]=1+\frac{1+r}{2+2 u}-\frac{1+r}{(2+2 u)+(2+2 r)} .
$$

The payoff of the mixed strategy and the pure strategy equilibrium are equal for $\beta_{0}=0$ and an empty interval $\beta_{1} \in\left[\frac{\beta_{0}(r+u)+u-r}{2+2 u-\beta_{0}}, \frac{\beta_{0}(1+r+u)+u-r}{2+2 u-\beta_{0}}\right)$. Consequently, the pure strategy payoff will be greater for $\beta_{0}=\xi>0$.

\section{Appendix E: Proof of Proposition 4}

Again, the proof consists of two steps:

Step 1: The creditor's payoff in the pure strategy equilibrium is given by

$$
E\left[\Pi^{\mathrm{C}}\left(\beta_{0}, \beta_{1}\right)\right]=\left(1-\beta_{0}\right) \theta^{*}+\left(1-\beta_{1}\right)\left(1-\theta^{* 2}\right) .
$$

Taking the partial derivatives with respect to $\beta_{1}$ yields 


$$
\begin{aligned}
\frac{\partial E\left[\Pi^{\mathrm{C}}\right]}{\partial \beta_{1}} & =\frac{\partial \theta^{*}}{\partial \beta_{1}}\left(1-\beta_{0}-\frac{\left(1-\beta_{1}\right) 2\left(\beta_{0}+u\right)}{2 \beta_{1}+r+u}\right)-\left(1-\theta^{* 2}\right) \\
& =\frac{1}{\left(2 \beta_{1}+r+u\right)^{3}}\left(2\left(\beta_{0}+u\right)\left(\beta_{0}(r+u+2)-r+u-2 \beta_{1}(1+u)\right)\right)-\left(1-\theta^{* 2}\right)
\end{aligned}
$$

and

$$
\frac{\partial E\left[\Pi^{\mathrm{C}}\right]}{\partial \beta_{0}}=\frac{\partial \theta^{*}}{\partial \beta_{0}}\left(1-\beta_{0}-\frac{\left(1-\beta_{1}\right) 2\left(\beta_{0}+u\right)}{2 \beta_{1}+r+u}\right)-\theta^{*} .
$$

A sufficient condition for $\frac{\partial E\left[\Pi^{\mathrm{C}}\right]}{\partial \beta_{0}}<0$ can be obtained from

$$
1-\beta_{0}-\frac{\left(1-\beta_{1}\right) 2\left(\beta_{0}+u\right)}{2 \beta_{1}+r+u}<0 \Leftrightarrow \beta_{0}>\frac{2 \beta_{1}(1+u)+r-u}{2+r+u}=\frac{2 \beta_{0}^{*}}{2+u+r}+\frac{2 \beta_{1} u}{2+u+r} .
$$

Inserting the efficient decision compensation $\beta_{0}=\beta_{0}^{*}=\beta_{1}+\frac{r-u}{2}$ into condition (48) yields $r+u>-2 \beta_{1}$, which holds for all $r, u>0$. Thus, the creditor's payoff will be maximal for $\beta_{0}<\frac{2 \beta_{1}(1+u)+r-u}{2+r+u}<\beta_{0}^{*}$.

Now consider $\frac{\partial E\left[\Pi^{\mathrm{C}}\right]}{\partial \beta_{1}}$. A sufficient condition for $\frac{\partial E\left[\Pi^{\mathrm{C}}\right]}{\partial \beta_{1}}<0$ can be obtained from $1-\beta_{0}-\frac{\left(1-\beta_{1}\right) 2\left(\beta_{0}+u\right)}{2 \beta_{1}+r+u}>0$. At $\beta_{0}=0$, this condition is equivalent to

$$
1-\frac{\left(1-\beta_{1}\right) 2 u}{2 \beta_{1}+r+u}>0 \Leftrightarrow 2 \beta_{1}(1+u)>-r+u \text {. }
$$

Thus, $\frac{\partial E\left[\Pi^{\mathrm{C}}\right]}{\partial \beta_{1}}<0$ at $\beta_{0}=0$ for all $r>u>0$. Furthermore,

$$
\frac{\partial^{2} E\left[\Pi^{\mathrm{C}}\right]}{\partial \beta_{1} \partial \beta_{0}}=\frac{1}{\left(2 \beta_{1}+r+u\right)^{3}}\left(4 r u-2 r+4 u^{2}+6 u-4 \beta_{1}+\beta_{0}\left(4 \beta_{1}+6 r+6 u+8\right)\right)
$$

continuously increases in $\beta_{0}$. Therefore, $\frac{\partial E\left[\Pi^{\mathrm{C}}\right]}{\partial \beta_{1}}$ is most strict at $\beta_{0}=\beta_{0}^{*}$. Inserting $\beta_{0}^{*}$ in $\frac{\partial E\left[\Pi^{\mathrm{C}}\right]}{\partial \beta_{1}}$ yields $-\frac{6 \beta_{1}+r+5 u}{4\left(2 \beta_{1}+r+u\right)}<0$, which is true for all $\beta_{1} \in(0,1)$ and $r, u>0$.

Thus, $\beta_{0}<\beta_{0}^{*}$ implies that $\beta_{1}=0$ will be optimal. We conclude that the optimal compensation in a pure strategy equilibrium consists of $\beta_{0}<\beta_{0}^{*}$ and $\beta_{1}=0$. Inserting $\beta_{1}=0$ into $\frac{\partial E\left[\Pi^{\mathrm{C}}\right]}{\partial \beta_{0}}=0$ yields the optimal compensation in the pure strategy equilibrium:

$$
\beta_{0}= \begin{cases}0 & \text { if } \mathrm{u}>-\frac{1+\mathrm{r}}{2}+\sqrt{\frac{(1+\mathrm{r})^{2}}{4}+\mathrm{r}} \\ \frac{r-u-u(r+u)}{2(1+r+u)} & \text { else. }\end{cases}
$$


The creditor's payoff amounts to

$$
E\left[\Pi^{\mathrm{C}}\right]= \begin{cases}1+\frac{r u}{(r+u)^{2}} & \text { if } \mathrm{u}>-\frac{1+\mathrm{r}}{2}+\sqrt{\frac{(1+\mathrm{r})^{2}}{4}+\mathrm{r}} \\ 1+\frac{1+u(2+u)}{4(1+r+u)} & \text { else }\end{cases}
$$

which is greater than $1 \forall u, r$.

Step 2 The creditor's payoff in the mixed strategy equilibrium with mistrusted continuation again will be smaller, as the payoff is $1-\beta_{0} \leq 1$.

It remains to show that the creditor's payoff in the mixed strategy equilibrium with mistrusted liquidation does not exceed the pure strategy payoff. This may arise for $\beta_{0} \in\left[\frac{r-u+2 \beta_{1}(1+u)}{1+\beta_{1}+r+u}, \frac{r-u+2 \beta_{1}(1+u)}{\beta_{1}+r+u}\right)$. First,

$$
\frac{\partial E\left[\Pi^{\mathrm{C}}\right]}{\partial \beta_{0}}=-\theta_{P}<0 \quad \forall u, r>0 .
$$

Thus, the optimal compensation is $\beta_{0}=\frac{r-u+2 \beta_{1}(1+u)}{1+\beta_{1}+r+u}$. Second, the partial derivative with respect to $\beta_{1}$ again yields

$$
\frac{\partial E\left[\Pi^{\mathrm{C}}\right]}{\partial \beta_{1}}=\frac{\partial \theta_{P}}{\partial \beta_{1}}\left(1-\beta_{0}-\frac{\left(1-\beta_{1}\right) 2 u}{2 \beta_{1}+u+r}\right)-\left(1-\theta_{P}{ }^{2}\right) .
$$

A sufficient condition $\frac{\partial E\left[\Pi^{\mathrm{C}}\right]}{\partial \beta_{1}}<0$ can be obtained from

$$
1-\beta_{0}-\frac{\left(1-\beta_{1}\right) 2 u}{2 \beta_{1}+u+r}>0 \Leftrightarrow \beta_{0}<\frac{r-u+2 \beta_{1}(1+u)}{2 \beta_{1}+r+u} .
$$

Condition (55) is most strict at $\beta_{0}=\frac{r-u+2 \beta_{1}(1+u)}{1+\beta_{1}+r+u}$. Inserting yields $\beta_{1}>-\frac{r-u}{2(1+u)}$, which is true for all $\beta_{1} \in(0,1)$ and $r>u$. Thus, the optimized creditor's compensation in the mixed strategy equilibrium with mistrusted liquidation for $\beta_{0}=$ $\frac{r-u+2 \beta_{1}(1+u)}{1+\beta_{1}+r+u}$ and $\beta_{1}=0$ yields

$$
E\left[\Pi^{\mathrm{C}}\right]=1+\frac{u\left(r u+r+u^{2}\right)}{(r+u)^{2}(r+u+1)},
$$

which is smaller than the payoffs in the pure strategy equilibrium for all $r>u$.

\section{Appendix F: Proof of Proposition 5}

1. Inserting $\hat{b}_{1}=0$ and reformulating $\frac{\partial E\left(\Pi^{\mathrm{C}}\right)}{\partial b_{0}}=0$ yield $\hat{b}_{0}=\frac{(1-u) r-u(1+u)}{2(u+r+1)}$ and $\theta^{*}=\frac{1+u}{2(u+r+1)} . \quad \hat{b}_{1}=0$ is equivalent to $\frac{\partial E\left(\Pi^{\mathrm{C}}\right)}{\partial b_{1}}<0$. This condition yields $u<-\frac{1+r}{2}+\sqrt{\frac{(1+r)^{2}}{4}+r}$. 
2. This case will be valid only if both $\frac{\partial E\left(\Pi^{\mathrm{C}}\right)}{\partial b_{0}}<0$ and $\frac{\partial E\left(\Pi^{\mathrm{C}}\right)}{\partial b_{1}}<0$. Inserting $\hat{b}_{0}=$ $\hat{b}_{1}=0$ and reformulating yields $-\frac{1+r}{2}+\sqrt{\frac{(1+r)^{2}}{4}+r}<u<\frac{1+r}{1-r} r$.

3. $\hat{b}_{1}$ is obtained from $\frac{\partial E\left(\Pi^{\mathrm{C}}\right)}{\partial b_{1}}=0$ and $u>\frac{1+r}{1-r} r$ from $\frac{\partial E\left(\Pi^{\mathrm{C}}\right)}{\partial b_{0}}<0$.

\section{Appendix G: Proof of Corollary 1}

1. Suppose $r<u<\frac{1+r}{1-r} r$. Comparing the critical values yields $\frac{u}{u+r}>\frac{1+u}{2+u+r} \Leftrightarrow u>r$. Expected creditor payoff under fixed and linear compensation is given by $E\left(\Pi_{\mathrm{fix}}^{\mathrm{C}}\right)=1+\frac{u}{u+r}-\frac{u^{2}}{(u+r)^{2}}$ and $E\left(\Pi_{\mathrm{lin}}^{\mathrm{C}}\right)=1$ $+\frac{1+r}{2+2 u}-\frac{1+r}{4+2 u+2 r}$. The expression $E\left(\Pi_{\mathrm{fix}}^{\mathrm{C}}\right)-E\left(\Pi_{\mathrm{lin}}^{\mathrm{C}}\right)>0$ is equivalent to

$$
\begin{aligned}
& (u-r)\left(2 r u^{2}+u\left(3 r^{2}+4 r-1\right)+r^{3}+2 r^{2}+r\right)>0 \leftrightarrow 2 r u^{2} \\
& \quad+u\left(3 r^{2}+4 r-1\right)+r^{3}+2 r^{2}+r>0 .
\end{aligned}
$$

Solving $2 r u^{2}+u\left(3 r^{2}+4 r-1\right)+r^{3}+2 r^{2}+r=0$ yields

$$
u_{1,2}=\frac{1-4 r-4 r^{2}}{4 r} \pm \sqrt{\left(\frac{1-4 r-4 r^{2}}{4 r}\right)^{2}-\frac{r^{3}+2 r^{2}+r}{2 r}} .
$$

The root term is negative for $r \in(0.1317,0.7673)$. In this case, the polynomial in the second part of (57) has no real valued root, and thus, (57) must be true. Consider $r<0.1317$ now. One can show that

$$
\frac{1-4 r-4 r^{2}}{4 r}-\sqrt{\left(\frac{1-4 r-4 r^{2}}{4 r}\right)^{2}-\frac{r^{3}+2 r^{2}+r}{2 r}}>\frac{1+r}{1-r} r
$$

for all $0 \leq r \leq 0.1317$, which implies inequality (57). If $r>0.7673$, then

$$
\frac{1-4 r-4 r^{2}}{4 r}+\sqrt{\left(\frac{1-4 r-4 r^{2}}{4 r}\right)^{2}-\frac{r^{3}+2 r^{2}+r}{2 r}}<r
$$

which again implies inequality (57). Thus, $E\left(\Pi_{\text {fix }}^{\mathrm{C}}\right)-E\left(\Pi_{\text {lin }}^{\mathrm{C}}\right)>0$ must be true for all valid $u$.

2. Suppose $u \geq \frac{1+r}{1-r} r$ now. Inequality $\frac{r+2 u+1}{2(u+r+1)}>\frac{1+u}{2+u+r}$ is equivalent to $r^{2}+(1+u) r+u>0$, which is true for all $u, r>0$. Expected creditor payoff under fixed compensation is $E\left(\Pi_{\mathrm{fix}}^{\mathrm{C}}\right)=\frac{r^{2}+6 r+4 u+5}{4(u+r+1)}$. Inequality $E\left(\Pi_{\mathrm{fix}}^{\mathrm{C}}\right)-$ $E\left(\Pi_{\text {lin }}^{\mathrm{C}}\right)>0$ can be written as

$$
(r+1)^{2}\left(u^{2}+(1+r) u-r\right)>0 \Leftrightarrow u^{2}+(1+r) u-r>0 .
$$

The roots of $u^{2}+(1+r) u-r$ are 


$$
u_{1,2}=-\frac{1+r}{2} \pm \sqrt{\left(\frac{1+r}{2}\right)^{2}+r} .
$$

Apparently, we obtain a positive and a negative root. We can show that the positive root $-\frac{1+r}{2}+\sqrt{\left(\frac{1+r}{2}\right)^{2}+r}$ must be smaller than $r$. Since $u>r, E\left(\Pi_{\mathrm{fix}}^{\mathrm{C}}\right)-$ $E\left(\Pi_{\text {lin }}^{\mathrm{C}}\right)>0$ is established.

\section{References}

Ayotte, Kenneth, and Hayong Yun. 2007. Matching Bankruptcy Laws to Legal Environments. The Journal of Law, Economics and Organization 25 (1): 2-30.

Baird, Douglas G. 1986. The Uneasy Case for Corporate Reorganizations. The Journal of Legal Studies 15 (1): 127-147.

Bernhardt, Dan, and Ed Nosal. 2004. Near-sighted Justice. The Journal of Finance 59 (6): 2655-2684.

Blazy, Regis, and Bertrand Chopard. 2004. Ex post efficiency of bankruptcy procedures: A general normative framework. International Review of Law and Economics 24 (4): 447-471.

Bris, Arturo, Alan Schwartz, and Ivo Welch. 2005. Who should Pay for Bankruptcy Costs? The Journal of Legal Studies 34 (2): 295-341.

Bulow, Jeremy I., and John B. Shoven. 1978. The Bankruptcy Decision. The Bell Journal of Economics 9 (2): 437-456.

Djankov, Simeon, Oliver Hart, Caralee McLiesh, and Andrei Shleifer. 2008. Debt enforcement around the world. Journal of Political Economy 116 (6): 1105-1149.

Franks, Julian R., and Gyongyi Loranth. 2013. A Study of Bankruptcy Costs and the Allocation of Control. Review of Finance 18 (3): 961-997.

Gertner, Robert, and David Scharfstein. 1991. A Theory of Workouts and the Effects of Reorganization Law. The Journal of Finance 46 (4): 1189-1222.

Giammarino, Ronald M. 1989. The Resolution of Financial Distress. The Review of Financial Studies 2 (1): $25-47$.

Haarmeyer, Hans, Wolfgang Wutzke, and Karsten Foerster. 2007. Insolvenzrechtliche Verguetung (InsVV). Commentary 4th ed. Muenchen: Beck.

Hotchkiss, Edith S., Kose John, Robert M. Mooradian, and Karin S. Thorburn. 2008. Bankruptcy and the Resolution of Financial Distress. In Handbook of Corporate Finance: Empirical Corporate Finance, ed. B. Espen Eckbo, vol. 2, chapter 14. North-Holland: Elsevier.

Kirchhof, Hans-Peter, Horst Eidenmueller, and Rolf Stuerner. 2014. Muenchener Kommentar zur Insolvenzordnung. Commentary 3rd ed. Muenchen: Beck.

Li, David D., and Shan Li. 1999. An agency theory of the bankruptcy law. International Review of Economics and Finance 8 (1): 1-24.

Mooradian, Robert M. 1994. The Effect of Bankruptcy Protection on Investment: Chapter 11 as a Screening Device. The Journal of Finance 49 (4): 1403-1430.

White, Michelle J. 1989. The Corporate Bankruptcy Decision. The Journal of Economic Perspective 3 (2): 129-151.

White, Michelle J. 1994. Corporate bankruptcy as a filtering device: Chapter 11 reorganizations and outof-court debt restructurings. The Journal of Law, Economics and Organization 10 (2): 268-295. 